\title{
Estimation of kinetic parameters related to biochemical interactions between hydrogen peroxide and signal transduction proteins
}

\author{
Paula M. Brito ${ }^{1,2,3}$ and Fernando Antunes ${ }^{4 *}$ \\ ${ }^{1}$ URIA-Centro de Patogénese Molecular, Faculdade de Farmácia, Universidade de Lisboa, Lisboa, Portugal \\ 2 Instituto de Medicina Molecular, Faculdade de Medicina da Universidade de Lisboa, Lisboa, Portugal \\ ${ }^{3}$ Faculdade de Ciências da Saúde, Universidade da Beira Interior, Covilhã, Portugal \\ ${ }^{4}$ Departamento de Química e Bioquímica and Centro de Química e Bioquímica, Faculdade de Ciências, Universidade de Lisboa, Lisboa, Portugal
}

\section{Edited by:}

Bulent Mutus, University of

Windsor, Canada

Reviewed by:

Peizhong Mao, Oregon Health and

Science University, USA

Saptarshi Kar, The University of

Western Australia, Australia

\section{*Correspondence:}

Fernando Antunes, Departamento de Química e Bioquímica and Centro de Química e Bioquímica, Faculdade de Ciências, Universidade de Lisboa, Campo Grande, P-1749-016 Lisboa, Portugal

e-mail: fantunes@fc.ul.pt
The lack of kinetic data concerning the biological effects of reactive oxygen species is slowing down the development of the field of redox signaling. Herein, we deduced and applied equations to estimate kinetic parameters from typical redox signaling experiments. $\mathrm{H}_{2} \mathrm{O}_{2}$-sensing mediated by the oxidation of a protein target and the switch-off of this sensor, by being converted back to its reduced form, are the two processes for which kinetic parameters are determined. The experimental data required to apply the equations deduced is the fraction of the $\mathrm{H}_{2} \mathrm{O}_{2}$ sensor protein in the reduced or in the oxidized state measured in intact cells or living tissues after exposure to either endogenous or added $\mathrm{H}_{2} \mathrm{O}_{2}$. Either non-linear fittings that do not need transformation of the experimental data or linearized plots in which deviations from the equations are easily observed can be used. The equations were shown to be valid by fitting to them virtual time courses simulated with a kinetic model. The good agreement between the kinetic parameters estimated in these fittings and those used to simulate the virtual time courses supported the accuracy of the kinetic equations deduced. Finally, equations were successfully tested with real data taken from published experiments that describe redox signaling mediated by the oxidation of two protein tyrosine phosphatases, PTP1B and SHP-2, which are two of the few $\mathrm{H}_{2} \mathrm{O}_{2}$-sensing proteins with known kinetic parameters. Whereas for PTP1B estimated kinetic parameters fitted in general the present knowledge, for SHP-2 results obtained suggest that reactivity toward $\mathrm{H}_{2} \mathrm{O}_{2}$ as well as the rate of SHP-2 regeneration back to its reduced form are higher than previously thought. In conclusion, valuable quantitative kinetic data can be estimated from typical redox signaling experiments, thus improving our understanding about the complex processes that underlie the interplay between oxidative stress and redox signaling responses.

Keywords: redox regulation, redox signaling, kinetics, rate constant, PTP1B, SHP-2, protein tyrosine phosphatases

\section{INTRODUCTION}

Being higher reductions states of molecular dioxygen, reactive oxygen species are present in all aerobic organisms. Initially, these species were seen as harmful species that caused or participated in the etiology of many diseases through oxidative damage, but more recently physiological roles mediated by the modulation of the redox state of biomolecules were attributed to reactive oxygen species (Sies, 2014). Today redox biology is an established field. As Berzelius put it the venom is in the dose, and reactive oxygen species have different roles depending on their concentration. This work is centered on hydrogen peroxide $\left(\mathrm{H}_{2} \mathrm{O}_{2}\right)$, a reactive oxygen species that has the properties of a second

Abbreviations: PTP1B, Protein tyrosine phosphatase 1; PTPs, protein tryrosine phosphatases; the Src homology 2 (SH2) domain containing phosphotyrosine phosphatase 2 (Shp-2). messenger (Forman et al., 2010) and participates in many pathways, including insulin (Mahadev et al., 2001; Haque et al., 2011), mitogenic (Irani et al., 1997), inflammatory, and apoptotic signaling (Oakley et al., 2009; Tschopp and Schroder, 2010). Having a relative low chemical reactivity, $\mathrm{H}_{2} \mathrm{O}_{2}$ reacts mainly with metal centers and with thiol compounds, such as cysteine residues in proteins (Marinho et al., 2014). Examples of $\mathrm{H}_{2} \mathrm{O}_{2}$ targets are PerR, a metal-dependent transcription factor that is inhibited by $\mathrm{H}_{2} \mathrm{O}_{2}$ in a Fenton-like reaction, and protein tyrosine phosphatases (PTPs), which are inhibited upon oxidation of cysteine residues in their active center (Tanner et al., 2011; Marinho et al., 2014; Sies, 2014). The list of proteins containing cysteine residues that were observed to be oxidized by $\mathrm{H}_{2} \mathrm{O}_{2}$ is vast, near 200 (Le Moan et al., 2006; Martínez-Acedo et al., 2012), and continues to increase as investigators find new targets for $\mathrm{H}_{2} \mathrm{O}_{2}$. In contrast, kinetic parameters concerning oxidation by $\mathrm{H}_{2} \mathrm{O}_{2}$ have been 
measured only for a few of these proteins (Ferrer-Sueta et al., 2011; Tanner et al., 2011), leading several researchers to point out the lack of proper quantitative data as a barrier to the development of the field (Brigelius-Flohé and Flohé, 2011; Buettner et al., 2013). Importantly, the triggering of biphasic responses by $\mathrm{H}_{2} \mathrm{O}_{2}$ in a narrow concentration range has important biological implications. For example, in H4IIEC hepatocytes $\mathrm{H}_{2} \mathrm{O}_{2}$ can either enhance or impair insulin signaling depending on its concentration (Iwakami et al., 2011). This dual role was attributed to the different sensitivity of PTP1B inhibition and JNK activation, two kinases that stimulate and inhibit insulin signaling, respectively. Thus, while $\mathrm{H}_{2} \mathrm{O}_{2}$ is an essential component of the insulin signaling pathway, it may also mediate the etiology of insulin resistance (Fisher-Wellman and Neufer, 2012). Although the underlying data is known for some time, such picture only emerged recently, probably because in absence of a quantitative framework, these biphasic responses were often interpreted as contradictory findings that were dependent of the biological model used or simply reflected non-reproducible experimental results. To study such complex responses it is advantageous to apply a quantitative and integrative approach typical of systems biology (Buettner et al., 2013), where the reactivity of targets toward $\mathrm{H}_{2} \mathrm{O}_{2}$ is determined to undercover which pathways operate in vivo under different conditions. In this work, we address how kinetic parameters can be determined from typical experiments performed in redox signaling.

Based on a simple reaction scheme representing $\mathrm{H}_{2} \mathrm{O}_{2}$ signaling, we started by deducing kinetic equations that are tailored to estimate kinetic parameters from experimental data. Next, to test the validity of the deduced equations, virtual experiments carried out under different conditions of $\mathrm{H}_{2} \mathrm{O}_{2}$ exposure were simulated with a kinetic model, and the results were fitted to the equations deduced. The agreement between the kinetic parameters obtained in these fittings and those used to obtain the virtual time courses was used as a criterion to decide on the accuracy of the kinetic equations deduced. Finally, to evaluate the applicability of kinetic equations to real data, experimental results described in the literature focusing on PTP-dependent signaling were fitted to the equations deduced. Two PTPs, PTP1B, and SHP-2, for which kinetic rate constants are known, were chosen as test cases. Our study demonstrates that insightful kinetic parameters related to biochemical interactions between $\mathrm{H}_{2} \mathrm{O}_{2}$ and signal transduction proteins can be estimated from typical $\mathrm{H}_{2} \mathrm{O}_{2}$-signaling experiments by applying the equations deduced here.

\section{THEORY AND METHODS MASTER EQUATION}

A minimal mathematical analytical model was set up to describe a signaling event triggered by $\mathrm{H}_{2} \mathrm{O}_{2}$, according to the following two reactions:

$$
\begin{gathered}
\text { Target }_{\mathrm{rd}}+\mathrm{H}_{2} \mathrm{O}_{2} \rightarrow \text { Target }_{\mathrm{ox}}+\mathrm{H}_{2} \mathrm{O} \\
\text { Target }_{\mathrm{ox}} \rightarrow \text { Target }_{\mathrm{rd}}
\end{gathered}
$$

In the first reaction, the reduced form of a sensor protein target $\left(\right.$ Target $_{\mathrm{rd}}$ ) is oxidized by $\mathrm{H}_{2} \mathrm{O}_{2}$, modifying its activity, which results in the modulation of a signaling pathway. In the second reaction, the oxidized target (Target $_{\mathrm{ox}}$ ) is switched-off by being regenerated back to the reduced form. A specific example of these two reactions is the inhibition of PTPs by oxidation of cysteine residues in their active center, which are reactivated upon reduction of this site; the temporary inhibition of these phosphatases increases the level of phosphorylation of their targets, thus promoting the signaling process. For these two reactions rate laws were defined as follows:

- For the $\mathrm{H}_{2} \mathrm{O}_{2}$-dependent oxidation step (1) $v_{1}=k_{\text {activation }} \times$ [Target ${ }_{\mathrm{rd}}$ ], where $k_{\text {activation }}=k_{\text {target }}+\mathrm{H}_{2} \mathrm{O} 2 \times\left[\mathrm{H}_{2} \mathrm{O}_{2}\right]$. $k_{\text {target }+\mathrm{H}_{2} \mathrm{O} 2}$ is the rate constant for the direct oxidation of the target protein by $\mathrm{H}_{2} \mathrm{O}_{2}$.

- For the switch-off step (2), $v_{2}=k_{\text {switchoff }} \times$ [Target $\left.{ }_{\text {ox }}\right]$. The total concentration of the target protein is assumed to be constant within the duration of the experiment $\left([\text { Target }]_{\text {total }}=\left[\right.\right.$ Target $\left._{\mathrm{ox}}\right]+\left[\right.$ Target $\left.\left._{\mathrm{rd}}\right]\right)$, and so $v_{2}=$ $k_{\text {switchoff }} \times\left([\text { Target }]_{\text {total }}-\left[\right.\right.$ Target $\left.\left._{r d}\right]\right)$.

Based on these two chemical reactions, the following differential equation was set up, where Target $_{r d}$ is the fraction of the target protein in the reduced state, $t$ is time, and $d / d t$ stands for the differential operator:

$$
\frac{d \text { Target }_{\mathrm{rd}}}{d t}=k_{\text {switchoff }}\left(1-\text { Target }_{\mathrm{rd}}\right)-k_{\text {activation }} \text { Target }_{\mathrm{rd}}
$$

The master equation describing the time course of Target $r$ is given by the analytical solution of Equation (3):

$$
\begin{aligned}
\text { Target }\left._{\text {rd }}\right|_{t}= & \frac{k_{\text {switchoff }}}{k_{\text {switchoff }}+k_{\text {activation }}}+e^{-\left(k_{\text {switchoff }}+k_{\text {activation }}\right) \times t} \\
& \times\left(\text { Target }\left._{\text {rd }}\right|_{0}-\frac{k_{\text {switchoff }}}{k_{\text {switchoff }}+k_{\text {activation }}}\right)
\end{aligned}
$$

With

$$
\text { Target }\left._{\mathrm{ox}}\right|_{t}=1-\text { Target }\left._{\mathrm{rd}}\right|_{t}
$$

Target $\left._{\text {rd }}\right|_{t}$ and Target $\left.{ }_{\text {ox }}\right|_{t}$ are the fractions of the target protein in the reduced and oxidized state at time $t$, respectively. Once the experimental variation of these fractions with time is known and the fraction of reduced target at time $\left.0{\text { ( } \text { Target }_{\mathrm{ox}}}_{0}\right|_{0}$ ) is measured, a non-linear fit to Equation (4) can be applied to estimate the kinetic parameters $k_{\text {activation }}$ and $k_{\text {switchoff }}$. One possibility is to estimate these two unknown parameters from a two-parameter non-linear fitting. Alternatively, if one of these parameters is already known, only the remaining unknown parameter is estimated from a one-parameter non-linear fitting.

Next, we linearized Equation (4) so that kinetic parameters can be determined from linear plots, in which deviations from the master Equation (4) are easier to observe. To linearize Equation (4), the steady-state (ss) fraction of protein present in the reduced form, Target $\left.{ }_{\text {ox }}\right|_{s s}$, was obtained by letting $t$ to tend to infinite, 
resulting in Equation (6):

$$
\text { Target }\left._{\mathrm{rd}}\right|_{s s}=\frac{k_{\text {switchoff }}}{k_{\text {switchoff }}+k_{\text {activation }}}
$$

Equation (6) was used to rewrite and linearize Equation (4) as Equations (7) and (8). If in the experimental time course this steady-state is not observed, Equation (4) cannot be linearized according to this procedure.

$$
\begin{aligned}
& \frac{\text { Target }\left._{\mathrm{rd}}\right|_{t}-\text { Target }\left._{\mathrm{rd}}\right|_{s s}}{\text { Target }\left._{\mathrm{rd}}\right|_{0}-\text { Target }\left._{\mathrm{rd}}\right|_{s s}}=e^{-\left(k_{\text {switchoff }}+k_{\text {activation }}\right) \times t} \\
& \ln \left(\frac{\text { Target }\left._{\mathrm{rd}}\right|_{t}-\text { Target }\left._{\mathrm{rd}}\right|_{s s}}{\text { Target }\left._{\mathrm{rd}}\right|_{0}-\text { Target }\left._{\mathrm{rd}}\right|_{s s}}\right)=-\left(k_{\text {switchoff }}+k_{\text {activation }}\right) \times
\end{aligned}
$$

A plot of $\ln \left(\frac{\text { Target }\left._{r d}\right|_{t}-\text { Target }\left._{r d}\right|_{s s}}{\operatorname{Target}_{r d} \mid 0-\text { Target }\left._{r d}\right|_{s s}}\right)$ vs. time gives a linear relationship with slope $=-\left(k_{\text {switchoff }}+k_{\text {activation }}\right)$.

Finally, combining this slope with Equation (6), kinetic parameters are estimated as:

$$
\begin{aligned}
& k_{\text {switchoff }}=- \text { slope } \times \text { Target }\left._{\text {reduced }}\right|_{\text {ss }} \\
& k_{\text {switchoff }}=- \text { slope }-k_{\text {switchoff }}
\end{aligned}
$$

\section{SIMPLIFICATION OF THE MASTER EQUATION}

Simplified forms of Equation (4) that apply to specific experimental conditions may constitute a useful alternative to estimate kinetic parameters.

\section{Absence of $\mathrm{H}_{2} \mathrm{O}_{2}$}

On the assumption that $k_{\text {activation }}=0$, i.e., $\mathrm{H}_{2} \mathrm{O}_{2}$ is absent in the system, Equation (4) was simplified as Equation (10).

$$
\text { Target }\left._{\mathrm{rd}}\right|_{t}-1=\left(\text { Target }\left._{\mathrm{rd}}\right|_{0}-1\right) \times e^{-k_{\text {switchoff }} \times t}
$$

Or

$$
\text { Target }\left._{\mathrm{ox}}\right|_{t}=\text { Target }\left._{\mathrm{ox}}\right|_{0} \times e^{-k_{\text {switchoff }} \times t}
$$

This equation is applied to determine $k_{\text {switchoff from time courses }}$ that follow the return of the sensor protein to its reduced form. Taking the logarithmic of both sides of Equation (10b):

$$
\ln \left(\text { Target }_{\mathrm{ox}} \mid t\right)=\ln \left(\text { Target }\left._{\mathrm{ox}}\right|_{0}\right)-k_{\text {switchoff }} \times t
$$

A plot of $\ln \left(\right.$ Target $\left.\left._{\mathrm{ox}}\right|_{t}\right)$ vs. time produces a straight line with $k_{\text {switchoff }}=-$ slope.

\section{No target reduction}

Equation (12), another simplified form of Equation (4), was obtained by ignoring target reduction, i.e., $k_{\text {switchoff }}=0$.

$$
\text { Target }\left._{\mathrm{rd}}\right|_{t}=\text { Target }\left._{\mathrm{rd}}\right|_{0} \times e^{-k_{\text {activation }} \times t}
$$

This equation is used to estimate $k_{\text {activation }}$ from short time courses when target reduction is still negligible. Taking the logarithmic of both sides of Equation (12):

$$
\ln \left(\text { Target }\left._{\mathrm{rd}}\right|_{t}\right)=\ln \left(\text { Target }\left._{\mathrm{rd}}\right|_{0}\right)-k_{\text {activation }} \times t
$$

A plot of $\ln \left(\right.$ Target $\left._{\mathrm{rd}} \mid t\right)$ vs. time produces a straight line with $k_{\text {activation }}=-$ slope.

\section{CONCENTRATION STUDIES}

In all previous equations, $\mathrm{H}_{2} \mathrm{O}_{2}$ is a hidden variable that influences $k_{\text {activation }}$ and kinetic parameters are estimated from experiments in which the time course of the oxidation state of the target protein is followed. If cells are exposed to various concentrations of $\mathrm{H}_{2} \mathrm{O}_{2}$, kinetic parameters may also be estimated by following the variation of the oxidation state of the target protein as a function of the $\mathrm{H}_{2} \mathrm{O}_{2}$ concentration at a given time point. To this end, $k_{\text {activation }}$ was replaced by $k_{\text {target }}+\mathrm{H}_{2} \mathrm{O} 2 \times\left[\mathrm{H}_{2} \mathrm{O}_{2}\right]$ in Equation (4), forming Equation (14):

$$
\begin{aligned}
\text { Target }\left._{\mathrm{rd}}\right|_{t}= & \frac{k_{\text {switchoff }}}{k_{\text {switchoff }}+k_{\text {target }}+\mathrm{H}_{2} \mathrm{O}_{2} \times\left[\mathrm{H}_{2} \mathrm{O}_{2}\right]} \\
& +e^{-\left(k_{\text {switch }}+k_{\text {target } \left.+\mathrm{H}_{2} \mathrm{O}_{2} \times\left[\mathrm{H}_{2} \mathrm{O}_{2}\right]\right) \times t}\left(\text { Target }\left._{\mathrm{rd}}\right|_{0}\right.\right.} \\
& \left.-\frac{k_{\text {switchoff }}}{k_{\text {switchoff }}+k_{\text {target }}+\mathrm{H}_{2} \mathrm{O}_{2} \times\left[\mathrm{H}_{2} \mathrm{O}_{2}\right]}\right)
\end{aligned}
$$

For a known fixed $t$, a non-linear two-parameter fitting of Target $\left.{ }_{\mathrm{rd}}\right|_{t}$ vs. $\left[\mathrm{H}_{2} \mathrm{O}_{2}\right]$ allows to estimate $k_{\text {switchoff }}$ and $k_{\text {target }}+\mathrm{H}_{2} \mathrm{O} 2$. As before, if one of the two parameters is already known a oneparameter non-linear fitting may be used to determine the other parameter.

Concerning Equation (8), after specifying the $\mathrm{H}_{2} \mathrm{O}_{2}$ concentration explicitly this equation became:

$$
\begin{aligned}
\ln \left(\frac{\text { Target }\left._{\mathrm{rd}}\right|_{t}-\text { Target }\left._{\mathrm{rd}}\right|_{s s}}{\text { Target }\left._{\mathrm{rd}}\right|_{0}-\text { Target }\left._{\mathrm{rd}}\right|_{s s}}\right)= & -k_{\text {switchoff }} \times t-k_{\text {target }}+\mathrm{H}_{2} \mathrm{O}_{2} \\
& \times t \times\left[\mathrm{H}_{2} \mathrm{O}_{2}\right]
\end{aligned}
$$

A plot of $\ln \left(\frac{\text { Target }\left._{\mathrm{rd}}\right|_{t}-\text { Target }\left._{\mathrm{rd}}\right|_{s s}}{\text { Target }_{\mathrm{rd}} \mid 0-\text { Target }\left._{\mathrm{rd}}\right|_{s s}}\right)$ vs. $\left[\mathrm{H}_{2} \mathrm{O}_{2}\right]$ gives a linear relationship with slope $=-k_{\text {target }}+\mathrm{H}_{2} \mathrm{O}_{2} \times t$ and intercept $=$ $-k_{\text {switchoff }} \times t$. In order to use this equation, the fraction of reduced target reached at steady-state $\left(\right.$ Target $\left._{\mathrm{rd}}\right|_{s s}$ ) must be known previously. Therefore, time courses are needed for each $\mathrm{H}_{2} \mathrm{O}_{2}$ concentration in order to obtain this value, which lessens the applicability of this equation.

In absence of target reduction, the equivalent of Equation (13) was deduced as:

$$
\begin{aligned}
\ln \left(\text { Target }_{\mathrm{rd}} \mid t\right)= & \ln \left(\text { Target }\left._{\mathrm{rd}}\right|_{0}\right) \\
& -k_{\text {target }}+\mathrm{H}_{2} \mathrm{O}_{2} \times t \times\left[\mathrm{H}_{2} \mathrm{O}_{2}\right]
\end{aligned}
$$

A plot of $\ln \left(\right.$ Target $\left._{\mathrm{rd}} \mid t\right)$ vs. $\left[\mathrm{H}_{2} \mathrm{O}_{2}\right]$ produces a straight line with slope $=-k_{\text {target }}+\mathrm{H}_{2} \mathrm{O}_{2} \times t$.

Importantly, the $\left[\mathrm{H}_{2} \mathrm{O}_{2}\right]$ in these equations refers to the intracellular $\left[\mathrm{H}_{2} \mathrm{O}_{2}\right]$ that reacts with the target. Therefore, in order to estimate $k_{\text {target }+\mathrm{H}_{2} \mathrm{O} 2}$, this concentration must be known. Intracellular $\left[\mathrm{H}_{2} \mathrm{O}_{2}\right]$ attained when cells are exposed to extracellular $\mathrm{H}_{2} \mathrm{O}_{2}$ can be estimated from the gradient between extracellular and intracellular $\mathrm{H}_{2} \mathrm{O}_{2}$. If this gradient is unknown, then 
these equations may be applied with the extracellular $\mathrm{H}_{2} \mathrm{O}_{2}$ concentrations, but the value of $k_{\text {target }}+\mathrm{H}_{2} \mathrm{O} 2$ obtained is referred to extracellular $\mathrm{H}_{2} \mathrm{O}_{2}$ concentrations, with the true value being higher. If instead $k_{\text {target }}+\mathrm{H}_{2} \mathrm{O} 2$ is known a priori, equations may be used to estimate the gradient between extracellular and intracellular $\mathrm{H}_{2} \mathrm{O}_{2}$.

\section{VALIDATION OF EOUATIONS}

To test the validity of the equations, the following mathematical kinetic model was set up. This model simulates ideal experiments in which cells are exposed to extracellular $\mathrm{H}_{2} \mathrm{O}_{2}$ or are stimulated to produce endogenous $\mathrm{H}_{2} \mathrm{O}_{2}$ in a receptor-mediated process. A key characteristic of these virtual experiments is that the kinetic parameters concerning $\mathrm{H}_{2} \mathrm{O}_{2}$ signaling are known a priori, corresponding to the kinetic parameters introduced in the model. Thus, by fitting the virtual time courses to the equations deduced previously, the validity of the equations can be tested objectively. If the equations are valid, kinetic parameters obtained in these fittings should be similar to those used in the kinetic model. In addition, by varying several parameters of the model, namely those concerning the experimental set up describing $\mathrm{H}_{2} \mathrm{O}_{2}$ exposure, experimental conditions in which the equations are valid may be defined.

The model is described by the following differential equations, which take into account two compartments, one referring to the extracellular space $\left(V_{\text {out }}\right)$ and the other to the cell volume $\left(V_{\text {in }}\right)$. Multicompartmentation was implemented as described previously (Alves et al., 2006).

$$
\begin{aligned}
& \frac{d\left[\mathrm{H}_{2} \mathrm{O}_{2}\right]_{\text {out }}}{d t}=\mathrm{H}_{2} \mathrm{O}_{2} \text { _production_out } \\
& +\mathrm{H}_{2} \mathrm{O}_{2} \_ \text {export } \times V_{\text {in }} / V_{\text {out }}-\mathrm{H}_{2} \mathrm{O}_{2} \text { _import } \\
& \frac{d\left[\mathrm{H}_{2} \mathrm{O}_{2}\right]_{\text {in }}}{d t}=\mathrm{H}_{2} \mathrm{O}_{2} \text { _production_in }+\mathrm{H}_{2} \mathrm{O}_{2} \text { _import } \\
& \times V_{\text {out }} / V_{\text {in }}-\mathrm{H}_{2} \mathrm{O}_{2} \text { _export }-\mathrm{v}_{-} \mathrm{GPx}-\mathrm{v}_{-} \text {Target } \\
& \frac{d\left[\text { target }_{\text {rd }}\right]}{d t}=\text { v_switch_off }- \text { v_Target }
\end{aligned}
$$

Reactions considered in the model (Table 1) were: extracellular production of $\mathrm{H}_{2} \mathrm{O}_{2}\left(\mathrm{H}_{2} \mathrm{O}_{2}\right.$ _production_out), which simulates, for example, production of $\mathrm{H}_{2} \mathrm{O}_{2}$ by glucose oxidase added to the incubation medium; intracellular production of $\mathrm{H}_{2} \mathrm{O}_{2}$ $\left(\mathrm{H}_{2} \mathrm{O}_{2}\right.$ _production_in), which simulates the endogenous production triggered by a receptor-mediated process; permeation of $\mathrm{H}_{2} \mathrm{O}_{2}$ across the plasma membrane into $\left(\mathrm{H}_{2} \mathrm{O}_{2}\right.$ _import $)$ and out of the cell $\left(\mathrm{H}_{2} \mathrm{O}_{2}\right.$ _export); consumption of $\mathrm{H}_{2} \mathrm{O}_{2}$ by an antioxidant enzyme (v_Gpx) and by a sensor protein target (v_Target); and finally, the switch-off mechanism of the target protein (v_switch_off). Table 2 shows the parameters used. Although kinetics and respective rate constants are based on published values, this model does not intend to model a particular cell or a specific signaling pathway. Reactivities of the target and the antioxidant enzyme toward $\mathrm{H}_{2} \mathrm{O}_{2}$ were based on that of PTP1B (Barrett et al., 1999) and glutathione peroxidase (GPx) (Flohe,

\begin{tabular}{|c|c|c|}
\hline Reaction & Name & Rate law \\
\hline$\rightarrow \mathrm{H}_{2} \mathrm{O}_{2 \text { out }}$ & $\mathrm{H}_{2} \mathrm{O}_{2}$ _production_out & $v_{-} \mathrm{H}_{2} \mathrm{O}_{2 \text { out }}$ \\
\hline$\rightarrow \mathrm{H}_{2} \mathrm{O}_{2 \mathrm{in}}$ & $\mathrm{H}_{2} \mathrm{O}_{2}$ _production_in & $\begin{array}{l}\mathrm{K}_{-} \mathrm{H}_{2} \mathrm{O}_{2 \text { in }} \text { or } \mathrm{k}_{-} \mathrm{H}_{2} \mathrm{O}_{2 \text { in }} \times \\
\text { sine }(\text { time } / 1200 \times 3.14)\end{array}$ \\
\hline $\mathrm{H}_{2} \mathrm{O}_{2 \text { out }} \rightarrow \mathrm{H}_{2} \mathrm{O}_{2 \text { in }}$ & $\mathrm{H}_{2} \mathrm{O}_{2}$ _import & Ps $\times A N_{\text {out }} \times\left[\mathrm{H}_{2} \mathrm{O}_{2 \text { out }}\right]$ \\
\hline $\mathrm{H}_{2} \mathrm{O}_{2 \text { in }} \rightarrow \mathrm{H}_{2} \mathrm{O}_{2 \text { out }}$ & $\mathrm{H}_{2} \mathrm{O}_{2}$ export & $P s \times A N_{\text {in }} \times\left[\mathrm{H}_{2} \mathrm{O}_{2 \mathrm{in}}\right]$ \\
\hline $\mathrm{H}_{2} \mathrm{O}_{2 \mathrm{in}} \stackrel{G P x}{\longrightarrow} \mathrm{H}_{2} \mathrm{O}$ & V_GPx & $k_{G P x} \times[G P x] \times\left[\mathrm{H}_{2} \mathrm{O}_{2 \text { in }}\right]$ \\
\hline $\begin{array}{l}\mathrm{H}_{2} \mathrm{O}_{2 \text { in }}+\text { Target }_{\text {rd }} \rightarrow \\
\text { Target }_{\text {ox }}+\mathrm{H}_{2} \mathrm{O}\end{array}$ & v_Target & $\begin{array}{l}k_{\text {Target }+\mathrm{H}_{2} \mathrm{O} 2} \times\left[\text { Target }_{\mathrm{rd}}\right] \\
\times\left[\mathrm{H}_{2} \mathrm{O}_{2 \text { in }}\right]\end{array}$ \\
\hline Target $_{\mathrm{ox}} \rightarrow$ Target $_{\mathrm{rd}}$ & v_switch_off & $\begin{array}{l}k_{\text {switchoff }} \times\left(\left[\text { Target }_{\text {tot }}\right]-\right. \\
\left.\left[\text { Target }_{\text {rd }}\right]\right)\end{array}$ \\
\hline
\end{tabular}
1979; Forstrom and Tappel, 1979), respectively. Levels of GPx, permeability constant for $\mathrm{H}_{2} \mathrm{O}_{2}$ across the plasma membrane,
Table 1 | Reactions and respective rate laws included in the kinetic model.

Table 2 | Parameter values used in the kinetic model.

\begin{tabular}{lclc}
\hline Parameter & Value & Parameter & Value \\
\hline$P S$ & $2.0 \mu \mathrm{m} \mathrm{s}^{-1}$ & $k_{G P x}$ & $6 \times 10^{7} \mathrm{M}^{-1} \mathrm{~s}^{-1}$ \\
$A$ & $627 \mu \mathrm{m}^{2}$ & $\mathrm{GPx}$ & $2 \times 10^{-7} \mathrm{M}$ \\
$V_{\text {in }}$ & $1472 \mu \mathrm{m}^{3}$ & $k_{\text {Target }+\mathrm{H} 2 \mathrm{O} 2}$ & $40 \mathrm{M}^{-1} \mathrm{~s}^{-1}$ \\
$V_{\text {out }}$ & $679 \times V_{\text {in }}$ & $k_{\text {switchoff }}$ & $1 \times 10^{-3} \mathrm{~s}^{-1}$ \\
$\mathrm{~V}_{-} \mathrm{H}_{2} \mathrm{O}_{2 \text { out }}$ & $(0-23.4) \times 10^{-7} \mathrm{M} \mathrm{s}^{-1}$ & Target tot & $8.3 \times 10^{-9} \mathrm{M}$ \\
$\mathrm{kH}_{2} \mathrm{O}_{2 \text { in }}$ & $(0-5) \times 10^{-3} \mathrm{M} \mathrm{s}^{-1}$ & & \\
\hline
\end{tabular}

All simulations used these parameters values; for cases where a range of values is indicated, the actual value used in the simulation is indicated in the respective figure legend.

$V_{\text {out }}$ and $V_{\text {in }}$ were taken from Antunes and Cadenas (2000). $k_{\text {switchoff }}$ was obtained from the lower range of values estimated in this work, based on previously published experiments. The resulting differential equations were solved numerically with PLAS (Voit, 1991). In the kinetic model, concentrations of Target ${ }_{r d}$ and Target ${ }_{\mathrm{ox}}$ were used. The respective fractions were calculated subsequently so that simulation data could be analyzed with the equations deduced here. The parameter $k_{\text {activation }}$ is not a rate constant in the numerical model, but it was calculated as $k_{\text {target }}+\mathrm{H}_{2} \mathrm{O} 2 \times\left[\mathrm{H}_{2} \mathrm{O}_{2 \text { in }}\right]$; when $\left[\mathrm{H}_{2} \mathrm{O}_{2 \text { in }}\right]$ was not constant, for example when a bolus addition of $\mathrm{H}_{2} \mathrm{O}_{2}$ or the endogenous nonconstant production of $\mathrm{H}_{2} \mathrm{O}_{2}$ was simulated, an average $\left[\mathrm{H}_{2} \mathrm{O}_{2 \text { in }}\right]$ was used.

\section{RESULTS}

As a first step to test the equations derived here, redox signaling experiments were simulated to generate data that was introduced into the equations in order to determine kinetic parameters. The validity of the equations was checked by comparing the kinetic parameters obtained with those used in the simulations.

\section{VALIDATION OF EQUATIONS WITH SIMULATED EXPERIMENTS}

The exposure of cell cultures to extracellular $\mathrm{H}_{2} \mathrm{O}_{2}$ initiates cellular responses that differ from those caused by the intracellular release of $\mathrm{H}_{2} \mathrm{O}_{2}$ triggered by receptor-mediated mechanisms (Forman, 2007), being the main difference the additional signal transduction pathways initiated in the first case. Nevertheless, the 
control of $\mathrm{H}_{2} \mathrm{O}_{2}$ delivery achieved by the extracellular exposure makes this approach more suitable for the purpose of estimating kinetic parameters. We simulated both approaches with the kinetic model described in Theory and Methods, starting with the extracellular exposure to $\mathrm{H}_{2} \mathrm{O}_{2}$.

\section{Extracellular addition of $\mathrm{H}_{2} \mathrm{O}_{2}$}

Cells may be exposed to extracellular $\mathrm{H}_{2} \mathrm{O}_{2}$ either by bolus additions or by incubation with steady-state concentrations of $\mathrm{H}_{2} \mathrm{O}_{2}$. In the bolus addition, a single dose of $\mathrm{H}_{2} \mathrm{O}_{2}$ is added to cells, constituting the most common method of exposing cell cultures to extracellular $\mathrm{H}_{2} \mathrm{O}_{2}$. It has the advantage of simplicity, but the results obtained are strongly dependent on the specific assay conditions (Marinho et al., 2013a). Among other factors, cell density and, for adherent-growing cells, the volume of incubation media dramatically affect the results.

In the steady-state methodology, exposure to $\mathrm{H}_{2} \mathrm{O}_{2}$ is calibrated so that cells are exposed for a known concentration of $\mathrm{H}_{2} \mathrm{O}_{2}$ that remains constant during the assay. Although more complex, this approach has much better experimental reproducibility with the actual $\mathrm{H}_{2} \mathrm{O}_{2}$ concentration in the assay being independent of experimental conditions. The implementation of this methodology is described in detailed in (Covas et al., 2013; Cyrne et al., 2013; Marinho et al., 2013a).
Steady-state. In the deduction of the kinetic equations, $k_{\text {activation }}$ $\left(k_{\text {target }}+\mathrm{H}_{2} \mathrm{O} 2 \times\left[\mathrm{H}_{2} \mathrm{O}_{2}\right]\right)$ was considered to be a constant parameter, i.e., $\mathrm{H}_{2} \mathrm{O}_{2}$ was assumed to be constant with time. So, as a positive control we started by analyzing the results simulated with a steady-state incubation, a case in which the equations tested should be valid.

In the first condition analyzed, cellular exposure to $\mathrm{H}_{2} \mathrm{O}_{2}$ (Figure 1A, curve 2) was long enough so that a balance between oxidation of the target that senses $\mathrm{H}_{2} \mathrm{O}_{2}$ and its regeneration was achieved. As observed in Figure 1A, curve 1, initially the target was oxidized until its oxidation state reached a near steadystate value as given by Equation (6). Simulated results were transformed according to Equation (8) (Figure 1B, blue line), with $k_{\text {activation }}$ and $k_{\text {switchoff }}$ being estimated from Equations $(9 \mathrm{~A})$ and (9B). The estimations obtained, $k_{\text {activation }}=8.1 \times 10^{-4} \mathrm{~s}^{-1}$ and $k_{\text {switchoff }}=1.0 \times 10^{-3} \mathrm{~s}^{-1}$, matched closely the respective expected values of $7.9 \times 10^{-4} \mathrm{~s}^{-1}$ and $1.0 \times 10^{-3} \mathrm{~s}^{-1}$, which were used in the simulations to draw curve 1 in Figure 1A. Note that the fitting to Equation (8) departed from linearity for longer time points (Figure 1B), when Target ${ }_{\text {rd }}$ approached its steady-state value (Figure 1B). This behavior was caused by small uncertainties in this value, which must be known in order to plot data according to Equation (8). As an alternative, the two parameters were also obtained from a non-linear fitting to

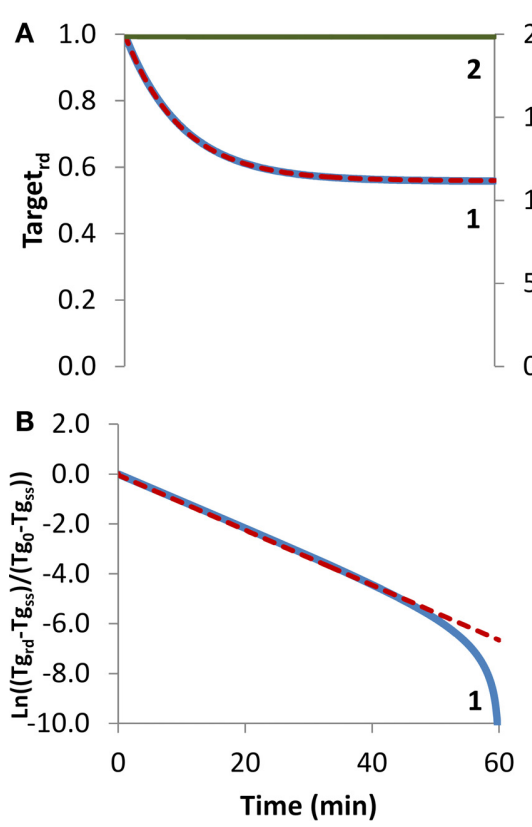

FIGURE 1 | Determination of kinetic parameters from simulated experiments when extracellular $\mathrm{H}_{\mathbf{2}} \mathrm{O}_{\mathbf{2}}$ was delivered as a steady-state. $\mathrm{H}_{2} \mathrm{O}_{2}$ concentration (curve 2, green line) was maintained during the duration of the experiment (A) or was stopped at $15 \mathrm{~min}$ (C). (A) The profile of the fraction of the $\mathrm{H}_{2} \mathrm{O}_{2}$ target in the reduced form (Target ${ }_{r d}$, blue line) was obtained by simulation of the kinetic model described in the Theory and Methods Section with $v_{-} \mathrm{H}_{2} \mathrm{O}_{2}$ out $=3.51 \times 10^{-7} \mathrm{M} \mathrm{s}^{-1}$ and $\left[\mathrm{H}_{2} \mathrm{O}_{2 \text { out }}\right]=3 \times 10^{-4} \mathrm{M}$ at time $=0$, (intracellular $\mathrm{H}_{2} \mathrm{O}_{2}$ production was absent, $\mathrm{k}_{-} \mathrm{H}_{2} \mathrm{O}_{2 \text { in }}=0$ ); red dashed line is the two-parameter non-linear fitting to Equation (4) used to estimate the kinetic parameters $k_{\text {activation }}$ and $k_{\text {switchoff }}$ (B) Fitting of the profile of Target ${ }_{r d}$ obtained in (A) to Equation

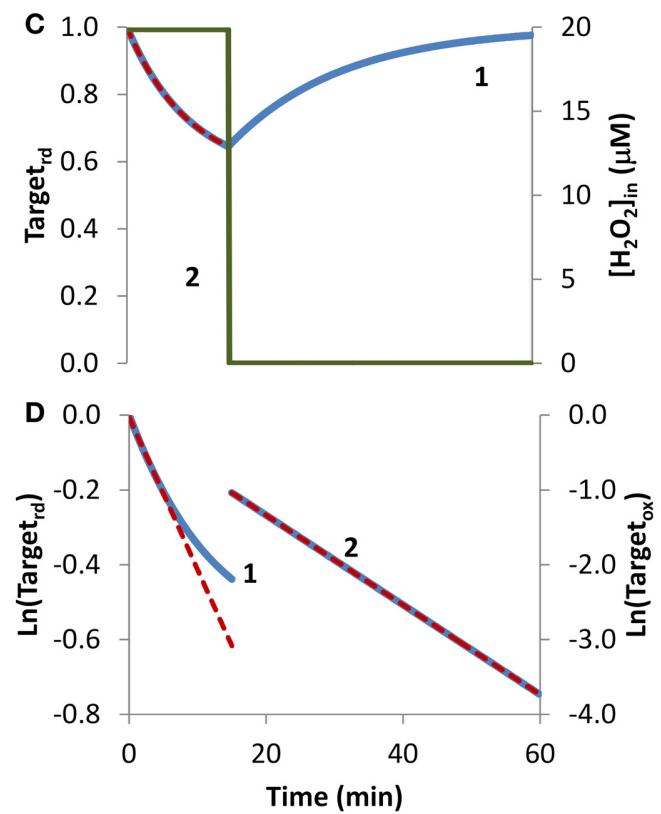

(8) (curve 1, blue line) using Target rd_o $_{\text {a }}=1$ and Target $_{\text {rd_ss }}=0.56$, ( $\mathrm{Tg}$ in $\mathrm{y}$-axis title means Target). $k_{\text {activation }}$ and $k_{\text {switchoff }}$ were estimated from the slope of the straight line by applying Equations (9A) and (9B). (C) The profile of the fraction of Target ${ }_{\text {rd }}$ (curve 1, blue line) was obtained as in (A) but $\mathrm{v}_{-} \mathrm{H}_{2} \mathrm{O}_{2}$ out and $\left[\mathrm{H}_{2} \mathrm{O}_{2}\right]_{\text {out }}$ were set to zero at $15 \mathrm{~min}$; red dashed line is the one-parameter non-linear fitting to Equation (4) in which $k_{\text {switchoff }}$ obtained in (D) curve 2 was used as an input to estimate $k_{\text {activation. }}$ (D) Target rd $_{\text {was }}$ fitted to Equation (13) (curve 1, left y-axis) while $\mathrm{H}_{2} \mathrm{O}_{2}$ was present, afterwards Targetox was fitted to Equation (11) (curve 2, right $y$-axis); $k_{\text {activation }}$ was estimated from the linear part of the fitting to Equation (13), $k_{\text {switchoff }}$ from the fitting to Equation (11). 
Equation (4) (Figure 1A, red dashed line), which neither requires data transformation nor knowing the value of the fraction of reduced target at steady-state. In this case, the estimated parameters, $k_{\text {activation }}=7.9 \times 10^{-4} \mathrm{~s}^{-1}$ and $k_{\text {switchoff }}=1.0 \times 10^{-3} \mathrm{~s}^{-1}$, matched exactly the expected values.

If the fraction of the reduced target does not reach a steadystate because, for example, a balance between its oxidation and regeneration is not attained before the exposure to $\mathrm{H}_{2} \mathrm{O}_{2}$ is terminated, Equation (8) cannot be applied. To illustrate this situation, a simulation was done under the exact same conditions as before with the exception that $\mathrm{H}_{2} \mathrm{O}_{2}$ exposure lasted only for $15 \mathrm{~min}$ (Figure 1C). Experimentally, this is equivalent to either replacing the external media to remove the $\mathrm{H}_{2} \mathrm{O}_{2}$ generating system, such as glucose oxidase, or by adding external catalase to the incubation media. This simulation was analyzed with Equation (13), an equation deduced ignoring the regeneration of the reduced form of the target. Good enough estimations were obtained by using only the first stage of the time course, when the degree of target oxidation was still low, and therefore the contribution of its regeneration to the time course of Target ${ }_{r d}$, could be ignored. From the slope of the initial linear part of the curve (Figure 1D, curve 1 ), a $k_{\text {activation }}=6.8 \times 10^{-4} \mathrm{~s}^{-1}$ was obtained, which was close to the expected value of $7.9 \times 10^{-4} \mathrm{~s}^{-1}$. Concerning $k_{\text {switchoff }}$, this kinetic parameter was estimated by fitting to Equation (11) the part of the curve starting after removal of external $\mathrm{H}_{2} \mathrm{O}_{2}$. Note that Equation (11) was deduced assuming reduction of the oxidized target when $\mathrm{H}_{2} \mathrm{O}_{2}$ was absent. An excellent linear plot was observed (Figure 1D, curve 2) with the estimated $k_{\text {switchoff }}$ of $1.0 \times 10^{-3} \mathrm{~s}^{-1}$ matching the expected value. Kinetic parameters were also obtained by non-linear fittings of Equation (4) to the first part of the curve when $\mathrm{H}_{2} \mathrm{O}_{2}$ was still present, either as a two-parameter non-linear fitting in which the two parameters $-k_{\text {activation }}$ and $k_{\text {switchoff }}$ - were determined, or as a one-parameter non-linear fitting, in which only one of the parameters was estimated, with the other being obtained from the linear plots of Figure 1B. If the conditions of the experimental assay fulfill all the assumptions applied to deduce Equation (4), a two-parameter non-linear fitting is the best choice, since both parameters are obtained without transformation of the experimental data. However, if the assumptions are not all fulfilled, which is the most common situation, we advise to apply a one-parameter non-linear fitting to Equation (4), inputting as a known parameter $k_{\text {switchoff }}$ estimated from Equation (11), being $k_{\text {activation }}$ the unknown parameter. As always whatever the option taken, the goodness of the fitting should be inspected. The dashed line in Figure 1C was obtained as a one-parameter non-linear fitting using $k_{\text {switchoff }}=1.0 \times 10^{-3} \mathrm{~s}^{-1}$ with the estimated $k_{\text {activation }}$ value of $7.9 \times 10^{-4} \mathrm{~s}^{-1}$ matching the expected value.

Overall, kinetic parameters estimated from simulated experiments in which $\mathrm{H}_{2} \mathrm{O}_{2}$ was delivered as a steady-state matched the expected values, validating the equations applied. This could be anticipated because Equation (4) relies on the key assumption that $\mathrm{H}_{2} \mathrm{O}_{2}$ concentration is constant during the experiment.

Bolus addition. The bolus addition set up, the most common experimental approach to expose cells to $\mathrm{H}_{2} \mathrm{O}_{2}$, was simulated in Figure 2. Upon incubation with a $1 \mathrm{mM}$ bolus addition, the $\mathrm{H}_{2} \mathrm{O}_{2}$ sensor was oxidized, the Target ${ }_{\mathrm{rd}}$ fraction reached a minimum at approximately $12 \mathrm{~min}$, then regeneration became more impor-

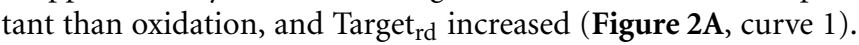
Kinetics of $\mathrm{H}_{2} \mathrm{O}_{2}$ consumption depends on the experimental set up, and under the conditions of this simulation, $\mathrm{H}_{2} \mathrm{O}_{2}$ was fully consumed after $60 \mathrm{~min}$ (Figure 2A, curve 2). Nevertheless, the general pattern observed in this simulation served as a test case to check how the non-constant $\mathrm{H}_{2} \mathrm{O}_{2}$ concentration impacts the estimation of kinetic parameters.

Because the fraction of reduced target never reached a constant value, Equation (8) was not applied, and instead Equation (13) was used to estimate $k_{\text {activation. }}$. Only the first part of the curve was considered (Figure 2B, curve 1), because shorter time courses minimize target regeneration, a process ignored by Equation (13). The $k_{\text {activation }}$ estimation of $1.8 \times 10^{-3} \mathrm{~s}^{-1}$ was close to the expected value of $1.7 \times 10^{-3} \mathrm{~s}^{-1}$. Concerning $k_{\text {switchoff, }}$ this parameter was estimated by fitting to Equation (11) the part of the curve after Target ${ }_{\text {rd }}$ reached its minimum (Figure 2B, curve 2). The presence of $\mathrm{H}_{2} \mathrm{O}_{2}$ in this part of the experiment promoted target oxidation, violating a key assumption behind Equation (11), and consequently deviations from linearity were observed. Even by using only the linear part of the curve, the $k_{\text {switchoff }}$ estimation of $6.7 \times 10^{-4} \mathrm{~s}^{-1}$
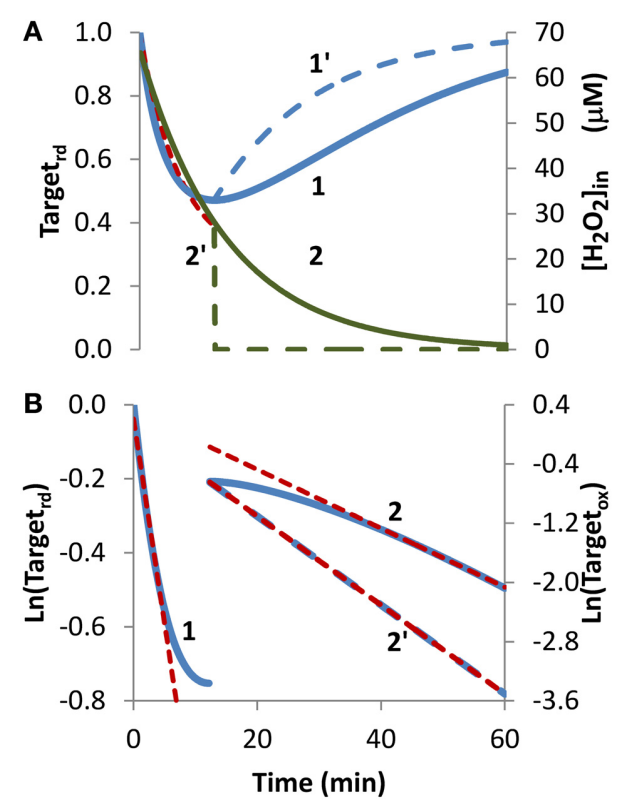

FIGURE 2 | Determination of kinetic parameters from simulated experiments when $\mathrm{H}_{\mathbf{2}} \mathrm{O}_{\mathbf{2}}$ was delivered as an extracellular bolus addition. (A) Curve 1 is the profile of Target rd $_{\text {fraction (blue line) obtained }}$ by simulation with $v_{-} \mathrm{H}_{2} \mathrm{O}_{2 \text { out }}=0 \mathrm{M} \mathrm{s}^{-1}$ and $\left[\mathrm{H}_{2} \mathrm{O}_{2 \text { out }}\right]=1 \times 10^{-3} \mathrm{M}$ at time $=0$, (intracellular $\mathrm{H}_{2} \mathrm{O}_{2}$ production was absent, $\mathrm{k}_{-} \mathrm{H}_{2} \mathrm{O}_{2 \text { in }}=0$ ). Curve $1^{\prime}$ is the profile of Target $t_{r d}$ (blue line) obtained as in curve 1 but $\left[\mathrm{H}_{2} \mathrm{O}_{2 \text { out }}\right]$ was set to zero at $12 \mathrm{~min}$; red dashed line is the one-parameter non-linear fitting to Equation (4) in which $k_{\text {switchoff }}$ obtained in (B) was used as an input to estimate $k_{\text {activation. }}$ (B) Until 12 min results were fitted to Equation (13) (curve 1, left y-axis), afterwards were fitted to Equation (11) (curve 2, right $y$-axis); $k_{\text {activation }}$ and $k_{\text {switchoff }}$ were estimated from the linear part of the fittings to Equations (13) and (11), respectively. 
underestimated the expected value of $1.0 \times 10^{-3} \mathrm{~s}^{-1}$. Removal of external $\mathrm{H}_{2} \mathrm{O}_{2}$ at $12 \mathrm{~min}$, when Target ${ }_{\mathrm{rd}}$ reached its minimum (Figure 2A, curve $2^{\prime}$ ), changed the regeneration profile of the $\mathrm{H}_{2} \mathrm{O}_{2}$ target (Figure 2A, curve $1^{\prime}$ ) and vastly improved the fitting to Equation (11) (Figure 2B, curve $2^{\prime}$ ) with the estimated $k_{\text {switchoff }}$ of $1.0 \times 10^{-3} \mathrm{~s}^{-1}$ matching exactly the expected value.

Concerning the non-linear fitting to Equation (4), a $k_{\text {activation }}=1.8 \times 10^{-3} \mathrm{~s}^{-1}$ was obtained when $k_{\text {switchoff }}=6.7 \times$ $10^{-4} \mathrm{~s}^{-1}$ was used as an input. Alternatively, by inputting a $k_{\text {switchoff }}=1.0 \times 10^{-3} \mathrm{~s}^{-1}$ a $k_{\text {activation }}=2.0 \times 10^{-3} \mathrm{~s}^{-1}$ was obtained.

Overall, these results indicate that the proposed equations can be applied to experiments in which $\mathrm{H}_{2} \mathrm{O}_{2}$ is delivered as a bolus addition. The accuracy of parameter estimation improves if $\mathrm{H}_{2} \mathrm{O}_{2}$ is removed at the time when the reduced form of the target reaches its minimum.

Concentration studies. Besides time courses, studies often evaluate how the concentration of $\mathrm{H}_{2} \mathrm{O}_{2}$ affects the oxidation state of the sensor target. We started by simulating the dependency of Target $_{r d}$ on external $\mathrm{H}_{2} \mathrm{O}_{2}$ concentration, delivered as a steadystate during $10 \mathrm{~min}$ (Figure 3A, curve 1). From the non-linear fitting to Equation (14), kinetic parameters that matched exactly the expected values were obtained $\left(k_{\text {target }}+\mathrm{H}_{2} \mathrm{O} 2=2.6 \mathrm{M}^{-1} \mathrm{~s}^{-1}\right.$ and $\left.k_{\text {switchoff }}=1.0 \times 10^{-3} \mathrm{~s}^{-1}\right)$. Note that $k_{\text {target }}+\mathrm{H}_{2} \mathrm{O} 2$ estimated from the fitting was based on external $\mathrm{H}_{2} \mathrm{O}_{2}$ concentrations. By considering the gradient between these and the intracellular $\mathrm{H}_{2} \mathrm{O}_{2}$ concentrations - 15 in the present simulation-the estimated value of the rate constant of $40 \mathrm{M}^{-1} \mathrm{~s}^{-1}$ for the reaction between the target and $\mathrm{H}_{2} \mathrm{O}_{2}$ matched the value used in the simulation. Results were also linearized and fitted to Equation (16) (curve 2 in Figure 3A), which was deduced assuming absence of target reduction, i.e., $k_{\text {switchoff }}=0 \mathrm{~s}^{-1}$. In this case, the estimated value of $1.7 \mathrm{M}^{-1} \mathrm{~s}^{-1}$ for $k_{\text {target }}+\mathrm{H}_{2} \mathrm{O} 2$, which was converted to $26 \mathrm{M}^{-1} \mathrm{~s}^{-1}$ when intracellular $\mathrm{H}_{2} \mathrm{O}_{2}$ concentrations were considered, underestimated the expected value.

To test how Equations (14) and (16) behave with data generated with bolus additions, the study of Figure $3 \mathbf{A}$ was repeated but now the $\mathrm{H}_{2} \mathrm{O}_{2}$ concentrations introduced in the equations were the initial bolus additions (Figure 3B, curve $1)$. Kinetic parameters obtained with the non-linear fitting to Equation (14) were $k_{\text {target }+\mathrm{H}_{2} \mathrm{O} 2}=2.0 \mathrm{M}^{-1} \mathrm{~s}^{-1}\left(\right.$ or $30 \mathrm{M}^{-1} \mathrm{~s}^{-1}$ if referred to intracellular $\left.\mathrm{H}_{2} \mathrm{O}_{2}\right)$, and $k_{\text {switchoff }}=1.3 \times 10^{-3} \mathrm{~s}^{-1}$. Linearization according to Equation (16) (curve 2 in Figure 3B) gave a $k_{\text {target }+\mathrm{H} 2 \mathrm{O} 2}$ of $1.2 \mathrm{M}^{-1} \mathrm{~s}^{-1}$, (or $18 \mathrm{M}^{-1} \mathrm{~s}^{-1}$ if referred to intracellular $\mathrm{H}_{2} \mathrm{O}_{2}$ ). As expected, these estimations were less accurate than those obtained when $\mathrm{H}_{2} \mathrm{O}_{2}$ was delivered as a steady-state, but nevertheless they constitute satisfactory semiquantitative estimations.

\section{Receptor-mediated endogenous $\mathrm{H}_{2} \mathrm{O}_{2}$ production}

The endogenous production of $\mathrm{H}_{2} \mathrm{O}_{2}$ upon cell stimulation by a ligand will give the best picture of the influence of $\mathrm{H}_{2} \mathrm{O}_{2}$ in a particular cell signaling pathway, as $\mathrm{H}_{2} \mathrm{O}_{2}$ production is both spatial and time restricted (Forman, 2007). Nevertheless, since the profile of $\mathrm{H}_{2} \mathrm{O}_{2}$ concentration generated is unknown this imposes

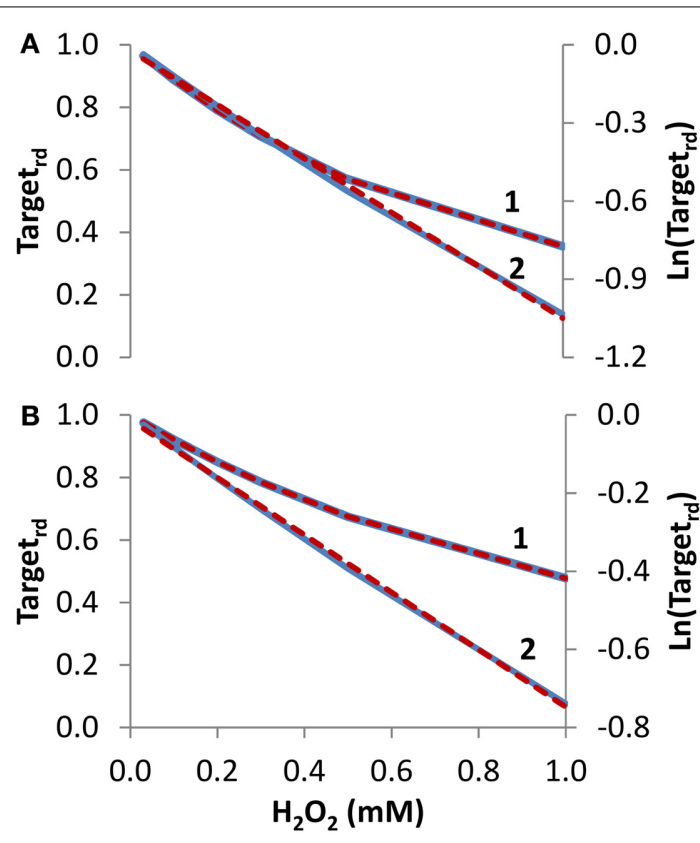

FIGURE 3 | Determination of kinetic parameters from simulated experiments when the concentration of extracellular $\mathrm{H}_{2} \mathrm{O}_{2}$ was changed. The reduced form of the target fraction (Target $t_{r d}$ ) obtained at $10 \mathrm{~min}$ is plotted as a function of either $\mathrm{H}_{2} \mathrm{O}_{2}$ steady-state concentrations in (A) or initial bolus additions in (B) (curves 1, blue linen). Simulations were run with $\mathrm{v}_{-} \mathrm{H}_{2} \mathrm{O}_{2}$ out varying in the range $(0.35-23.4) \times 10^{-7} \mathrm{M} \mathrm{s}^{-1}$ and $\left[\mathrm{H}_{2} \mathrm{O}_{2 \text { out }}\right]$ in the range $(0.03-1) \times$ $10^{-3} \mathrm{M}$ at time $=0$ in $\mathrm{A}$, while in $\mathrm{B} \mathrm{v}_{-} \mathrm{H}_{2} \mathrm{O}_{2}$ out was set to zero and $\left[\mathrm{H}_{2} \mathrm{O}_{2 \text { out }}\right]$ was changed in the range $(0.03-1) \times 10^{-3} \mathrm{M}$ at time $=0$; intracellular $\mathrm{H}_{2} \mathrm{O}_{2}$ production was absent $\left(\mathrm{k}_{-} \mathrm{H}_{2} \mathrm{O}_{2 \text { in }}=0\right)$ in both cases. In (A,B), results were analyzed with non-linear fits of Target rd $_{\text {d }}$ to Equation (14) (curve 1, red dashed line) in order to estimate

$k_{\text {target }+\mathrm{H}_{2} \mathrm{O} 2}$ and $k_{\text {switchoff, }}$ or they were linearized according to Equation (16) (curve 2, blue line) with $k_{\text {target }+\mathrm{H}_{2} \mathrm{O} 2}$ being estimated from the slopes of the red dashed lines.

potential problems to the determination of kinetic parameters. To test how the kinetic equations behave under such circumstances, we started by simulating a case where $\mathrm{H}_{2} \mathrm{O}_{2}$ intracellular production was rapidly triggered and then set at a near constant value. This scenario worked as positive control and was analyzed as described previously for the extracellular addition of steadystate $\mathrm{H}_{2} \mathrm{O}_{2}$. The kinetic parameters obtained matched exactly the expected values or were very close to these values depending on the fittings applied (not shown). Nevertheless, this scenario is seldom achieved when $\mathrm{H}_{2} \mathrm{O}_{2}$ is produced endogenously, and next we tested the kinetic equations under non-constant $\mathrm{H}_{2} \mathrm{O}_{2}$ intracellular production.

$\mathrm{H}_{2} \mathrm{O}_{2}$ endogenous production was simulated with a sine-like function: there was an initial increase in the $\mathrm{H}_{2} \mathrm{O}_{2}$ concentration, reaching its maximum at $10 \mathrm{~min}$, and then a decrease until $\mathrm{H}_{2} \mathrm{O}_{2}$ production stopped at $20 \mathrm{~min}$ (Figures $4 \mathrm{~A}, \mathrm{C}$, curve 2). In this context, two scenarios were simulated. In the first, $\mathrm{H}_{2} \mathrm{O}_{2}$ production was high enough so that a near constant level of reduced target was observed (Figure 4A, curve 1), and accordingly results were fitted to Equation (8). The presence of a non-constant $\mathrm{H}_{2} \mathrm{O}_{2}$ production caused deviations from linearity (Figure 4B, curve 
1). Nevertheless results obtained from the near-linear intermediate portion of the curve gave estimations, $k_{\text {switchoff }}=7.8 \times$ $10^{-4} \mathrm{~s}^{-1}$ and $k_{\text {activation }}=1.2 \times 10^{-2} \mathrm{~s}^{-1}$, that compared well with the expected parameters, $k_{\text {switchoff }}=1.0 \times 10^{-3} \mathrm{~s}^{-1}$ and $k_{\text {activation }}=1.0 \times 10^{-2} \mathrm{~s}^{-1}$. As before, $k_{\text {switchoff }}$ was also obtained from the second part of the curve by fitting data to Equation (11) (Figure 4B, curve 2), giving a $k_{\text {switchoff }}=7.6 \times 10^{-4} \mathrm{~s}^{-1}$, an underestimation of the expected value. As described for the bolus addition, removal of $\mathrm{H}_{2} \mathrm{O}_{2}$ from the system after Target ${ }_{\mathrm{rd}}$ reached its minimum improved the estimations (not shown). In real experiments, the effect of this addition will be dependent on whether removal of extracellular $\mathrm{H}_{2} \mathrm{O}_{2}$ decreases the localized intracellular levels of $\mathrm{H}_{2} \mathrm{O}_{2}$. If this occurs, a change in the reduction profile of the oxidized target should be observed. In this simulation, the application of non-linear fittings did not improve the estimations of kinetic parameters: from a non-linear fitting where $k_{\text {switchoff }}=7.6 \times 10^{-4} \mathrm{~s}^{-1}$ was used as input (dashed line in Figure 4A) a $k_{\text {activation }}$ of $0.51 \times 10^{-2} \mathrm{~s}^{-1}$ was obtained (Figure 4A, dashed line) and a two-parameter non-linear fitting did not improve these estimations.

In the second simulation in which endogenous production of $\mathrm{H}_{2} \mathrm{O}_{2}$ followed a sine-like function, a constant level of reduced target was not observed (Figure 4C, curve 1). The $k_{\text {activation }}$ estimation of $1.0 \times 10^{-3} \mathrm{~s}^{-1}$, obtained from the linear portion of the plot according to Equation (13) (Figure 4D, curve 1), matched the expected value. The $k_{\text {switchoff }}$ estimation of $9.3 \times$ $10^{-4} s^{-1}$, obtained from the second part of the curve after fitting data to Equation (11) (Figure 4D, curve 2), was close to the expected value of $1.0 \times 10^{-3} \mathrm{~s}^{-1}$. A one-parameter non-linear fitting (Figure 4C, dashed line) gave a $k_{\text {activation }}$ of $1.0 \times 10^{-3} \mathrm{~s}^{-1}$, i.e., the expected value, when a $k_{\text {switchoff }}$ of $9.3 \times 10^{-4}$ was used as input.

Overall, when $\mathrm{H}_{2} \mathrm{O}_{2}$ production is not constant deviations from the equations derived here are expected. Nevertheless, estimated kinetic parameters are still satisfactory at a semiquantitative level, and the deviations from linearity in the plots proposed here may be used as a useful tool to diagnose a nonconstant $\mathrm{H}_{2} \mathrm{O}_{2}$ production.

\section{FITS TO EXPERIMENTAL DATA}

The use of simulation data was useful to test the validity of the equations deduced and to figure out how deviations from the assumptions behind their deduction affected the estimation of kinetic parameters. Nevertheless, simulation data points are virtually infinite and devoid of experimental error; in contrast real experiments contain a finite number of measurements with associated experimental error. To test how equations cope with these issues, they were applied to data obtained from the literature for two PTPs, PTP1B and SHP-2.

\section{$\mathrm{H}_{2} \mathrm{O}_{2}$-external delivery}

Two experiments in which $\mathrm{H}_{2} \mathrm{O}_{2}$ was added externally as a bolus addition (Figure 5) were analyzed. In the first experiment (Rinna et al., 2006), the time course of PTP1B oxidation was followed in a
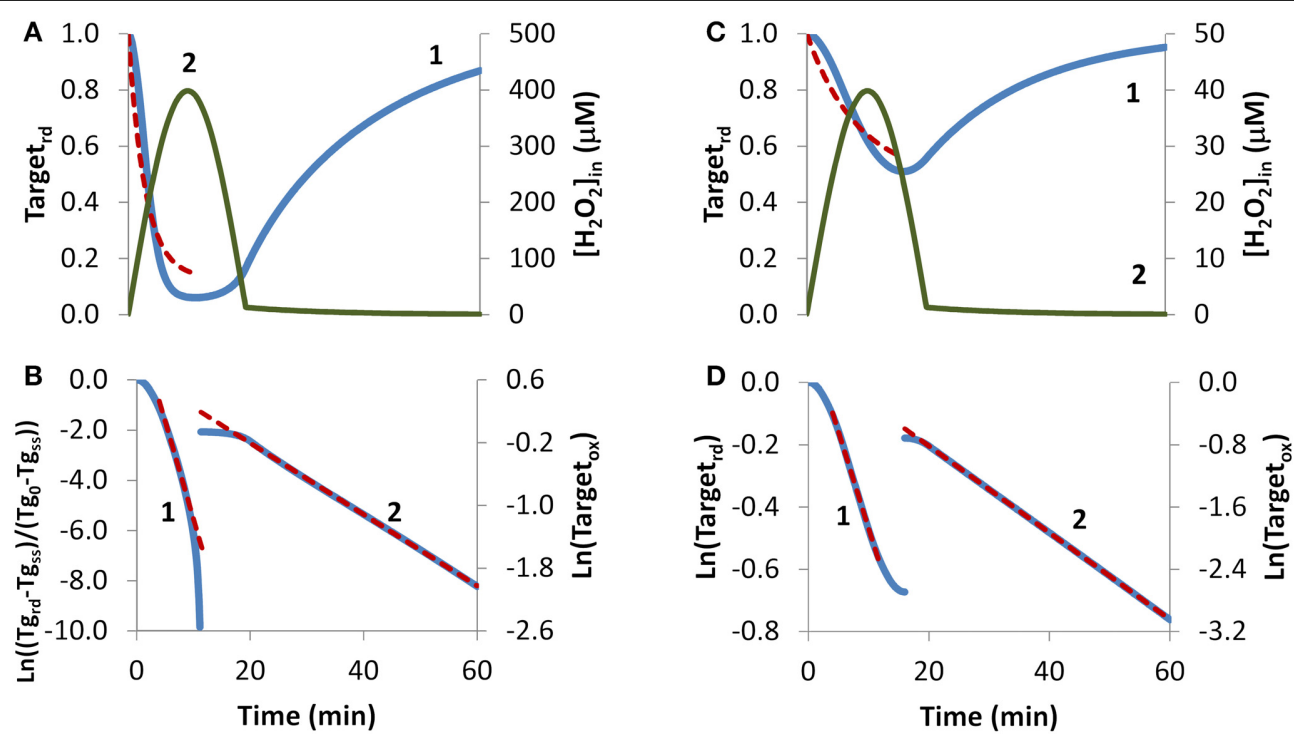

FIGURE 4 | Determination of kinetic parameters from simulated experiments when $\mathrm{H}_{2} \mathrm{O}_{\mathbf{2}}$ was produced endogenously. A non-constant sine-like $\mathrm{H}_{2} \mathrm{O}_{2}$ intracellular exposure (green lines) was simulated as $\mathrm{kH}_{2} \mathrm{O}_{2 \text { in }}$ $\times$ sine $($ time $/ 1200 \times 3.14$ ), (extracellular production was absent,

$\mathrm{v}_{-} \mathrm{H}_{2} \mathrm{O}_{2}$ out $=0$ ). (A) Profile of Target rd $_{\text {f }}$ fraction (blue line) was simulated with $\mathrm{kH}_{2} \mathrm{O}_{2 \text { in }}=5 \times 10^{-3} \mathrm{M} \mathrm{s}^{-1}$; red dashed line is the one-parameter non-linear fitting to Equation (4) in which $k_{\text {switchoff }}$ obtained in (B) curve 2 was used as an input to estimate $k_{\text {activation. }}$ (B) The first part of the profile (until $11.3 \mathrm{~min}$ ) of Target rd $_{\text {d }}$ was fitted to Equation (8) (curve 1, blue line) using Target trd_o $_{2}=1$ and Target $_{\text {rd_ss }}=0.06$; the kinetic parameters $k_{\text {activation }}$ and $k_{\text {switchoff }}$ were

obtained from the slope of near-linear intermediate portion of the curve by applying Equations (9A) and (9B). After $11.3 \mathrm{~min}$, the profile of Target ox was fitted to Equation 13, from which $k_{\text {switchoff }}$ was estimated. (C) The profile of Target $_{\text {rd }}$ fraction (blue line) was obtained as in (A), but with

$\mathrm{kH}_{2} \mathrm{O}_{2 \text { in }}=0.5 \times 10^{-3} \mathrm{M} \mathrm{s}^{-1}$; red dashed line is the one-parameter non-linear

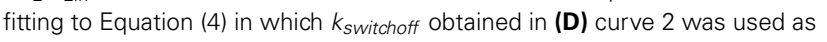
an input to estimate $k_{\text {activation. }}$ (D) Target rd $_{\text {d }}$ was fitted to Equation (13) (curve 1, left y-axis) until 16.0 min, afterwards, Target ox was fitted to Equation (11) (curve 2 , right $y$-axis); $k_{\text {activation }}$ and $k_{\text {switchoff }}$ were estimated from the linear part of the fittings to Equations (13) and (11), respectively. 
rat alveolar macrophage cell line after addition of a $100 \mu \mathrm{M} \mathrm{H}_{2} \mathrm{O}_{2}$ bolus dose for $15 \mathrm{~min}$ (Figure 5A, curve 1). By fitting data to Equation (4) with a two parameter non-linear fitting, a $k_{\text {activation }}$ of $1.1 \times 10^{-3} \mathrm{~s}^{-1}$ and a $k_{\text {switchoff }}$ of $2.6 \times 10^{-3} \mathrm{~s}^{-1}$ were estimated. Alternatively, when results were linearized according to Equation (13) (Figure 5A, curve 2) a $k_{\text {activation }}$ of $0.59 \times 10^{-3} \mathrm{~s}^{-1}$ was obtained, after discarding the $15 \mathrm{~min}$ point. Note that also with simulation data a similar deviation from linearity at late time points was observed (Figure $\mathbf{2 B}$, curve 1). By considering an external $\mathrm{H}_{2} \mathrm{O}_{2}$ concentration of $100 \mu \mathrm{M}$, the apparent firstorder rate constant $k_{\text {activation }}$ in the range $(0.59-1.1) \times 10^{-3} \mathrm{~s}^{-1}$ was converted to a rate constant between the target and $\mathrm{H}_{2} \mathrm{O}_{2}$ $\left(k_{\text {target }}+\mathrm{H}_{202}\right)$ of $5.9-11 \mathrm{M}^{-1} \mathrm{~s}^{-1}$. This value refers to extracellular $\mathrm{H}_{2} \mathrm{O}_{2}$, and so if the gradient between extracellular and intracellular $\mathrm{H}_{2} \mathrm{O}_{2}$ was considered the value of $k_{\text {target }}+\mathrm{H}_{2} \mathrm{O} 2$ for PTP1B would be higher.

In the second experiment, rat-1 fibroblasts were subjected to $\mathrm{H}_{2} \mathrm{O}_{2}$ bolus additions in the range $0-500 \mu \mathrm{M}$ for $1 \mathrm{~min}$, followed by the measurement of the oxidation level of SHP-2 (Meng et al.,
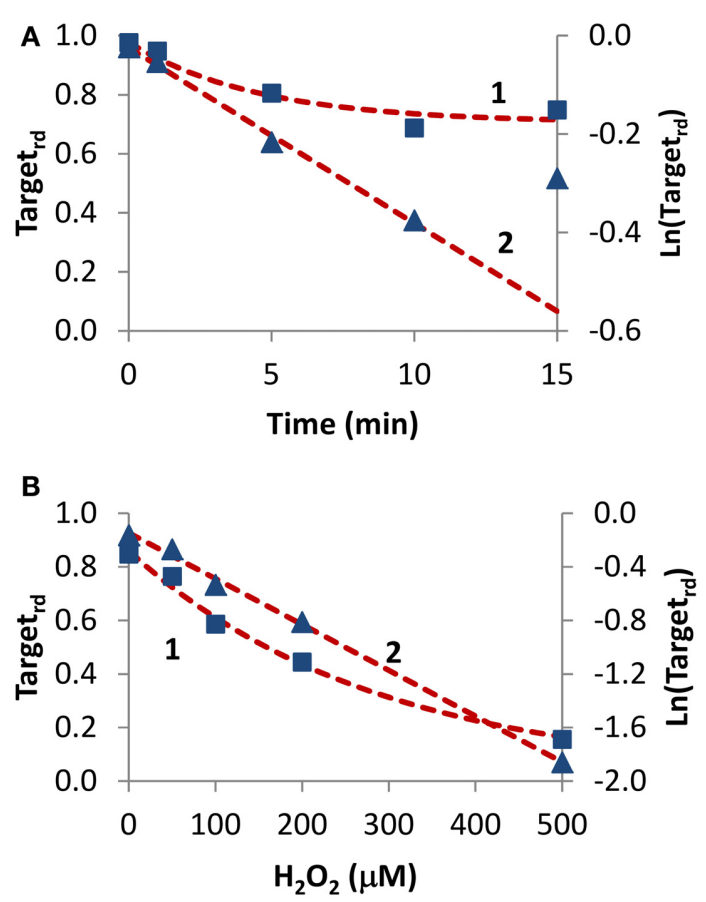

FIGURE 5 | Determination of kinetic parameters from experiments when $\mathrm{H}_{2} \mathrm{O}_{2}$ was delivered as an extracellular bolus addition. (A) Data (ם) was taken from Figure 1 in Rinna et al. (2006). Gel was digitalized and analyzed with ImageJ (Rasband, 1997); fraction of oxidized target was calculated assuming a maximum level of oxidation of $31 \%$ (Rinna et al., 2006). Time course was fitted to Equation (4), with $k_{\text {activation }}$ and $k_{\text {switchoff }}$ as variables (curve 1, left $y$-axis), or was linearized $(\boldsymbol{\Delta})$ and fitted to Equation (13) (curve 2, right y-axis). (B) Data ( $\mathbf{\square}$ ) was taken from Figure 2A in Meng et al. (2002). Gel was digitalized and analyzed with ImageJ (Rasband, 1997); fraction of oxidized protein tyrosine phosphatase corresponding to $70 \mathrm{kDa}$ (SHP-2) was calculated assuming that complete oxidation was achieved by $1 \mathrm{mM} \mathrm{H}_{2} \mathrm{O}_{2}$. Time course was fitted to Equation (14), with $k_{\text {target }}+\mathrm{H}_{2} \mathrm{O} 2$ and $k_{\text {switchoff }}$ as variables (curve 1 , left $y$-axis), or was linearized $(\boldsymbol{\Lambda})$ and fitted to Equation (16) (curve 2, right y-axis).
2002) (Figure 5B, curve 1). After fitting data to Equation (14) (Figure 5B, curve 1) with a two parameter non-linear fitting, a $k_{\text {target }+\mathrm{H} 2 \mathrm{O} 2}$ of $60 \mathrm{M}^{-1} \mathrm{~s}^{-1}$ and a $k_{\text {switchoff }}$ of $1.3 \times 10^{-3} \mathrm{~s}^{-1}$ were estimated. Linearization according to Equation (16) gave a $k_{\text {target }+\mathrm{H} 2 \mathrm{O} 2}$ of $57 \mathrm{M}^{-1} \mathrm{~s}^{-1}$ (Figure 5B, curve 2). Again, $k_{\text {target }}+\mathrm{H}_{2} \mathrm{O} 2$ values refer to extracellular $\mathrm{H}_{2} \mathrm{O}_{2}$ concentrations. Even if a bolus addition was used, because short-term incubations of 1 min were done, the assumption of constant $\mathrm{H}_{2} \mathrm{O}_{2}$ behind the deduction of Equations (14) and (16) was verified.

\section{Receptor-mediated signaling}

To test how equations behave when analyzing receptor-mediated signaling, the following two experiments were considered. In the first, A431 human epidermoid carcinoma cells were stimulated by EGF, triggering $\mathrm{H}_{2} \mathrm{O}_{2}$ intracellular production that lead to PTP1B oxidation and inhibition (Figures 6A,B), while in the second experiment, rat-1 cells were stimulated with PDGF inducing SHP-2 oxidation (Figures 6C,D). In both cases, the profile of PTP oxidation did not reach a near steady-state, precluding the application of Equation (8). Concerning $k_{\text {switchoff }}$, estimations of $1.9 \times 10^{-3} \mathrm{~s}^{-1}$ and $8.7 \times 10^{-3} \mathrm{~s}^{-1}$ were obtained, respectively for $\mathrm{PTP} 1 \mathrm{~B}$ and $\mathrm{SHP}-2$ reactivation, after fitting to Equation (11) the second part of the PTP oxidation curves (curves 2 in Figures 6B,D). For $k_{\text {activation }}$, estimations of $1.0 \times 10^{-3} \mathrm{~s}^{-1}$ and $9.3 \times 10^{-3} \mathrm{~s}^{-1}$ were obtained, respectively for PTP1B and SHP-2, after applying Equation (13) to linearize the first part of the PTP oxidation profile (curve 1 in Figures 6B,D). These $k_{\text {activation }}$ values were close to those obtained from non-linear fittings, $2.0 \times 10^{-3} \mathrm{~s}^{-1}$ and $9.7 \times 10^{-3} \mathrm{~s}^{-1}$ for PTP1B and SHP-2, respectively (dashed lines in Figures 6A,C).

Overall, data taken from literature fitted well to the equations deduced here, even if experiments analyzed were carried out without any special concern considering their application to estimate kinetic parameters.

\section{DISCUSSION}

Herein, we deduced equations to determine kinetic parameters from typical redox signaling experiments in which $\mathrm{H}_{2} \mathrm{O}_{2}$ is either added externally to cells or is endogenously produced following receptor activation by diverse cellular stimuli. The equations were shown to be accurate after fitting them to data generated by simulations. We also performed simulations in which the assumption that $\mathrm{H}_{2} \mathrm{O}_{2}$ is constant during the experiment was not fulfilled, that is, $\mathrm{H}_{2} \mathrm{O}_{2}$ was delivered as a bolus addition, or the endogenous production of $\mathrm{H}_{2} \mathrm{O}_{2}$ was not constant. Under these conditions, deviations from linearity were observed when simulation results were plotted according to the linear equations we deduced. Nevertheless, the estimated kinetic parameters were close to the parameters introduced in the simulations. Finally, we tested the application of the equations to real experiments with published experimental data concerning the $\mathrm{H}_{2} \mathrm{O}_{2}$ signaling mediated by inhibition of PTPs, namely PTP1B and SHP-2. While in general excellent fittings were obtained, in some cases deviations as those observed when $\mathrm{H}_{2} \mathrm{O}_{2}$ was added as a bolus addition were observed. In general, the estimated kinetic parameters (Table 3) are consistent with the published rate constants. 

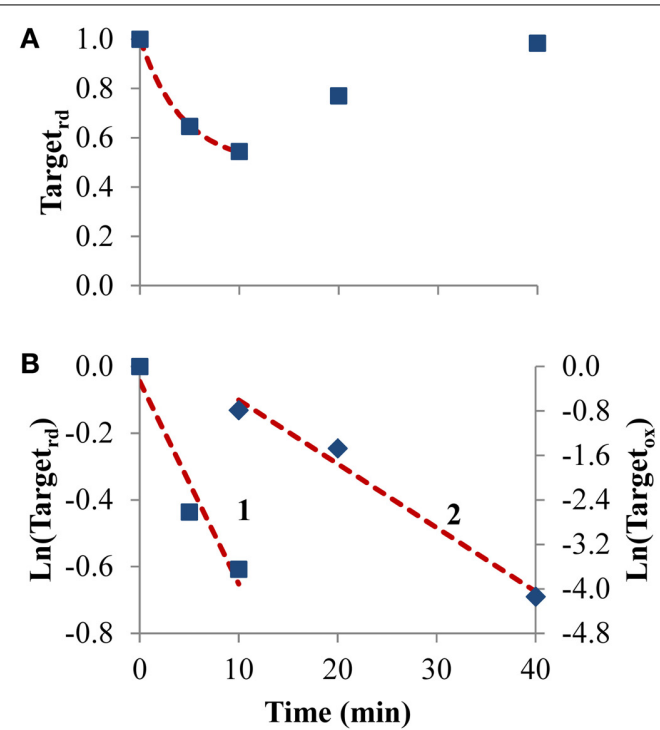

FIGURE 6 | Determination of kinetic parameters from experiments where intracellular $\mathrm{H}_{2} \mathrm{O}_{2}$ production was triggered by cell stimulation. (A) Data concerning PTP1B oxidation following stimulation of A431 cells with EGF (ם) was taken from Figure 2 in Lee et al. (1998). (C) Data concerning SHP-2 oxidation following stimulation of rat-1 cells by PDGF was taken from gel in Figure 4 in Meng et al. (2002) after digitalization and analysis with ImageJ (Rasband, 1997), and assuming that $100 \%$ of oxidation of SHP-2 was achieved in absence of iodoacetic acid as
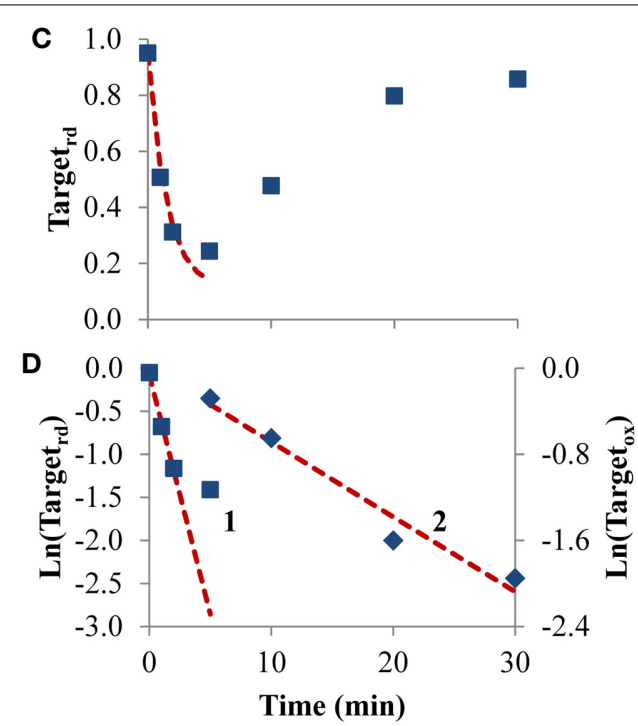

described in Meng et al. (2002). The red dashed lines in $(\mathbf{A}, \mathbf{C})$ are one-parameter non-linear fittings to Equation (4) in which $k_{\text {switchoff }}$ values obtained from curves 2 in (B,D), respectively, were used as input to estimate $k_{\text {activation. }}$ (B,D) Linearization of data shown in $(\mathbf{A}, \mathbf{C})$, respectively; results in the first part of the experiment were fitted to Equation (13) (curves 1, left y-axis), afterwards were fitted to Equation (11) (curves 2, right $y$-axis); kactivation was estimated from the fitting to Equation (13), $k_{\text {switchoff }}$ from the fitting to Equation (11).

Table 3 | Kinetic parameters estimated in this work based on the analysis of published data.

\begin{tabular}{|c|c|c|c|c|}
\hline \multirow[t]{2}{*}{ PTP } & \multicolumn{2}{|r|}{$\boldsymbol{k}_{\text {switchoff }}$} & \multirow{2}{*}{$\frac{k_{\text {target }+} \mathrm{H}_{2} \mathrm{O} 2}{\text { External } \mathrm{H}_{2} \mathrm{O}_{2}}$} & \multirow{2}{*}{$\begin{array}{c}\text { k activation } \\
\text { Receptor-mediated } \mathrm{H}_{2} \mathrm{O}_{2} \text { production }\end{array}$} \\
\hline & External $\mathrm{H}_{2} \mathrm{O}_{2}$ & Receptor-mediated $\mathrm{H}_{2} \mathrm{O}_{2}$ production & & \\
\hline PTP1B & $2.6 \times 10^{-3} \mathrm{~s}^{-1}$ & $1.9 \times 10^{-3} s^{-1}$ & $5.9-11 \mathrm{M}^{-1} \mathrm{~s}^{-1}$ & $(1-2) \times 10^{-3} s^{-1}$ \\
\hline SHP-2 & $1.3 \times 10^{-3} \mathrm{~s}^{-1}$ & $8.7 \times 10^{-3} \mathrm{~s}^{-1}$ & $57-60 \mathrm{M}^{-1} \mathrm{~s}^{-1}$ & $(9.3-9.7) \times 10^{-3} \mathrm{~s}^{-1}$ \\
\hline
\end{tabular}

Apparent first-order rate constant for the reactivation of PTP $\left(k_{\text {switchoff }}\right)$, the rate constant for the inactivation of PTP by extracellular $\mathrm{H}_{2} \mathrm{O}_{2}\left(k_{\text {target }}+\mathrm{H} 2 \mathrm{O} 2\right)$, and the apparent first-order rate constant for this activation ( $\left.k_{\text {activation }}=k_{\text {target }+\mathrm{H}_{2} \mathrm{O} 2} \times\left[\mathrm{H}_{2} \mathrm{O}_{2}\right]\right)$ are shown.

Concerning the parameters describing redox signal switchingoff ( $\left.k_{\text {switchoff }}\right)$, which in the case of the PTPs analyzed here corresponds to their reactivation, the results summarized in Table 3 constitute, as far as we know, the first cell-based kinetic estimates for this process. This characterization is relevant because modulation of PTP reactivation regulates cell signaling (Dagnell et al., 2013). For PTP1B, $k_{\text {switchoff values in the }}$ range (1.9-2.6) $\times 10^{-3} \mathrm{~s}^{-1}$ were estimated, which are plausible taking into account the known data for PTP1B reactivation. In vitro, reduced thioredoxin $(2 \mu \mathrm{M})$ reactivates oxidized PTP1B with an apparent rate constant of $1.4 \times 10^{-3} \mathrm{~s}^{-1}$ (Parsons and Gates, 2013), which corresponds to a rate constant of $700 \mathrm{M}^{-1} \mathrm{~s}^{-1}$ for this reaction. Thus, considering this rate constant and the $k_{\text {switchoff }}$ values determined here, we estimate the cellular concentration of reduced thioredoxin to be $2-3 \mu \mathrm{M}$. This range is close to the value observed experimentally in Jurkat T-cells, $0.43 \mu \mathrm{M}$ (Adimora et al., 2010), with the difference observed being easily account for different cell lines used or by the participation of alternative thioredoxinrelated proteins, like the redoxin TRP14, in the reactivation of PTP1B (Dagnell et al., 2013). This agreement further strengths the validity of the approach we purpose here to reveal kinetic information hidden in typical redox signaling experiments.

For SHP-2, $k_{\text {switchoff }}$ was estimated in the range $(1.3-8.7) \times$ $10^{-3} \mathrm{~s}^{-1}$ (Table 3), which is similar or higher than the range estimated for PTP1B. This is unexpected because the reactivity of SHP-2 toward thioredoxin is about 20 times lower than PTP1B (Parsons and Gates, 2013). Either the cell line rat-1, where SHP-2 reactivation data was obtained (Meng et al., 2002), contains much higher levels of thioredoxin or an alternative system other than thioredoxin is reactivating SHP-2. The second alternative is supported by the observation that in cells lacking thioredoxin reductase TrxR1, a key partner of thioredoxin that keeps it in the reduced state, SHP-2 oxidation remains unchanged (Dagnell et al., 2013). 
Concerning the oxidation of PTPs by $\mathrm{H}_{2} \mathrm{O}_{2}$, rate constants estimated from experiments in which extracellular $\mathrm{H}_{2} \mathrm{O}_{2}$ was added were 5.9-11 M $\mathrm{M}^{-1} \mathrm{~s}^{-1}$ for PTP1B and 57-60 M $\mathrm{M}^{-1} \mathrm{~s}^{-1}$ for SHP-2 (Table 3). These values were calculated based on the external $\mathrm{H}_{2} \mathrm{O}_{2}$ concentrations added to cells. The actual $\mathrm{H}_{2} \mathrm{O}_{2}$ concentration that oxidizes these targets is lower as $\mathrm{H}_{2} \mathrm{O}_{2}$ gradients across the plasma membrane are established when cells are incubated with extracellular $\mathrm{H}_{2} \mathrm{O}_{2}$ (Antunes and Cadenas, 2000; Marinho et al., 2013b). Thus, the value of these rate constants will be higher if they are based on the actual intracellular $\mathrm{H}_{2} \mathrm{O}_{2}$ concentrations that oxidize PTPs. For PTP1B, rate constants obtained in kinetic studies with purified PTP1B are in the range 9-43 $\mathrm{M}^{-1} \mathrm{~s}^{-1}$ (Denu and Tanner, 1998; Barrett et al., 1999; Zhou et al., 2011; Marinho et al., 2014), and so a gradient between the extracellular and the intracellular concentration of $\mathrm{H}_{2} \mathrm{O}_{2}$ at the site of PTP1B oxidation is estimated to be in the range 2-7 for the experiments analyzed in this work, which matches the lower range of known gradients for human cell lines (Antunes and Cadenas, 2000; Makino et al., 2004; De Oliveira-Marques et al., 2007; Oliveira-Marques et al., 2013). However, gradients as high as 650 have been recently estimated taking into account the participation of peroxiredoxin (Huang and Sikes, 2014), whose role in the degradation of $\mathrm{H}_{2} \mathrm{O}_{2}$ is still an open issue (Benfeitas et al., 2014). Thus, the rate constants obtained for PTP1B fit the known quantitative data for the reactivity of this PTP with $\mathrm{H}_{2} \mathrm{O}_{2}$.

For SHP-2, the estimated rate constants of $57-60 \mathrm{M}^{-1} \mathrm{~s}^{-1}$ (Table 3) for its oxidation by $\mathrm{H}_{2} \mathrm{O}_{2}$ were higher than those determined in vitro with purified SHP-2, which are in the range 9-15 $\mathrm{M}^{-1} \mathrm{~s}^{-1}$ (Chen et al., 2009; Zhou et al., 2011). Moreover, if the gradient of $\mathrm{H}_{2} \mathrm{O}_{2}$ across the plasma membrane is taken into account this difference will be even higher. Several possible explanations may account for this discrepancy. First, kinetic rate constants obtained in vitro with purified proteins may not reflect rate constants under in vivo conditions (Van Eunen et al., 2010 , 2012). Second, peroxy-derivatives such as peroxymonocarbonate (Trindade et al., 2006; Zhou et al., 2011) and peroxymonophosphate (LaButti et al., 2007), which have higher reactivity with PTPs than $\mathrm{H}_{2} \mathrm{O}_{2}$, could be the actual species that oxidize SHP-2. Third, the primary sensor of $\mathrm{H}_{2} \mathrm{O}_{2}$ may not be SHP-2 but a high-reactive target that slowly relays the oxidation to SHP-2 (Winterbourn and Hampton, 2008; Forman et al., 2010; Brigelius-Flohé and Flohé, 2011; Ferrer-Sueta et al., 2011). Note that the models described here do not distinguish between a mechanism in which a low-reactive sensor is slowly oxidized by $\mathrm{H}_{2} \mathrm{O}_{2}$, from a mechanism in which a highreactive sensor is rapidly oxidized by $\mathrm{H}_{2} \mathrm{O}_{2}$ and then, through a thiol-disulfide reshuffling transfer reaction, slowly oxidizes a low reactive sensor such as SHP-2. In general, known data about redox signaling pathways is consistent with either of these two scenarios (Marinho et al., 2014). Distinguishing between these possible alternative mechanisms will be possible after collecting rate constants in several cell lines upon the generalized application of the equations deduced here to redox signaling experiments.

The kinetic parameters estimated from experiments in which cells are activated by receptor-mediated pathways indicated that the apparent first-order rate constant for the oxidation of SHP-2 is about 5 times higher than that for PTP1B (Table 3). Because $k_{\text {activation }}=k_{\text {target }}+\mathrm{H}_{2} \mathrm{O} 2 \times\left[\mathrm{H}_{2} \mathrm{O}_{2}\right]$, either the localized $\mathrm{H}_{2} \mathrm{O}_{2}$ intracellular concentration is higher in the experiment in which SHP-2 oxidation was observed, or $k_{\text {target }}+\mathrm{H}_{2} \mathrm{O} 2$ is higher for SHP2 than for PTP1B, or both. In this regard, the EGF receptor, the $\mathrm{H}_{2} \mathrm{O}_{2}$ producing enzyme NOX2, and SHP-2 immunoprecipitated all together (Paulsen et al., 2012), supporting the possibility of a highly localized $\mathrm{H}_{2} \mathrm{O}_{2}$ signaling pool. For PTP1B, from the $k_{\text {activation }}$ estimation of (1.0-2.0) $\times 10^{-3} \mathrm{~s}^{-1}$ the local intracellular $\mathrm{H}_{2} \mathrm{O}_{2}$ concentration reached locally in A431 cells, when stimulated by EGF under the experimental conditions described in Lee et al. (1998), is estimated to be in the range $23-220 \mu \mathrm{M}$, assuming a $k_{\text {target }}+\mathrm{H} 2 \mathrm{O} 2$ value in the range $9-43 \mathrm{M}^{-1} \mathrm{~s}^{-1}$. Such local concentrations, particularly those in the low range of these values, can potentially be reached upon the concerted action of local production of $\mathrm{H}_{2} \mathrm{O}_{2}$ by NADPH oxidases (Chen et al., 2008; Mishina et al., 2011; Paulsen et al., 2012) and localized inhibition of $\mathrm{H}_{2} \mathrm{O}_{2}$ removing enzymes (Woo et al., 2010; Rawat et al., 2013). In addition, it can also be suggested that $\mathrm{H}_{2} \mathrm{O}_{2}$ diffusion out of membrane-entrapped signaling microcompartments may be constrained, because biomembranes constitute a regulable barrier for $\mathrm{H}_{2} \mathrm{O}_{2}$ diffusion (Antunes and Cadenas, 2000; Branco et al., 2004; Bienert et al., 2007; Miller et al., 2010).

While the equations deduced here were applied successfully to typical signaling experiments, a few alterations in the way experiments are carried out will improve the accuracy of parameter estimation. When cells are exposed to extracellular $\mathrm{H}_{2} \mathrm{O}_{2}$, we suggest a steady-state delivery so that $\mathrm{H}_{2} \mathrm{O}_{2}$ is constant during the experiment (Marinho et al., 2013a), a key assumption considered in the deduction of the equations. If the use of a bolus addition is absolutely needed, we suggest short-term experiments so that the $\mathrm{H}_{2} \mathrm{O}_{2}$ decay caused by its cellular consumption is less significant. Finally, removal of $\mathrm{H}_{2} \mathrm{O}_{2}$ by adding catalase or replacing extracellular incubation media without $\mathrm{H}_{2} \mathrm{O}_{2}$, during the second part of the experiment when target reduction starts to predominate, improves the estimation of $k_{\text {switchoff }}$ values. This last suggestion may also be applied when $\mathrm{H}_{2} \mathrm{O}_{2}$ production is triggered by a receptor-mediated mechanism following cell stimulation.

In conclusion, the application of the equations deduced here to typical redox-signaling experiments reveals valuable quantitate kinetic information. Of note, the equations described require only measuring the relative levels of oxidation of a $\mathrm{H}_{2} \mathrm{O}_{2}$ sensor target and not absolute concentrations, thus facilitating their application to most experiments. While equations were tested with PTP signaling, they can be applied to other proteins that react with $\mathrm{H}_{2} \mathrm{O}_{2}$, such has thiol-proteins and those containing metalcenters. Being characterized by the presence of both multiple parallel pathways and biphasic effects, redox regulation is a field that will benefit from the widespread determination of kinetic parameters. Such knowledge is important to distinguish apparent contradictory biological effects of reactive oxygen species that are involved in pathological damaging pathways and, at the same time, are part of normal functional signaling pathways. In this way, the present knowledge on redox signaling and oxidative stress would be more efficiently translated into therapeutic applications. 


\section{ACKNOWLEDGMENTS}

Supported by Fundação para a Ciência e a Tecnologia (FCT), Portugal (PEst-OE/QUI/UI0612/2013 and VIH/SAU/0020/2011).

\section{REFERENCES}

Adimora, N. J., Jones, D. P., and Kemp, M. L. (2010). A model of redox kinetics implicates the thiol proteome in cellular hydrogen peroxide responses. Antioxid. Redox Signal. 13, 731-743. doi: 10.1089/ars.2009.2968

Alves, R., Antunes, F., and Salvador, A. (2006). Tools for kinetic modeling of biochemical networks. Nat. Biotechnol. 24, 667-672. doi: 10.1038/ nbt0606-667

Antunes, F., and Cadenas, E. (2000). Estimation of $\mathrm{H} 2 \mathrm{O} 2$ gradients across biomembranes. FEBS Lett. 475, 121-126. doi: 10.1016/S0014-5793(00) 01638-0

Barrett, W. C., DeGnore, J. P., Konig, S., Fales, H. M., Keng, Y. F., Zhang, Z. Y., et al. (1999). Regulation of PTP1B via glutathionylation of the active site cysteine 215. Biochemistry (Mosc.) 38, 6699-6705. doi: 10.1021/bi990240v

Benfeitas, R., Selvaggio, G., Antunes, F., Coelho, P. M. B. M., and Salvador, A. (2014). Hydrogen peroxide metabolism and sensing in human erythrocytes: a validated kinetic model and reappraisal of the role of peroxiredoxin II. Free Radic. Biol. Med. 74, 35-49. doi: 10.1016/j.freeradbiomed.2014. 06.007

Bienert, G. P., Møller, A. L. B., Kristiansen, K. A., Schulz, A., Møller, I. M., Schjoerring, J. K., et al. (2007). Specific aquaporins facilitate the diffusion of hydrogen peroxide across membranes. J. Biol. Chem. 282, 1183-1192. doi: 10.1074/jbc.M603761200

Branco, M. R., Marinho, H. S., Cyrne, L., and Antunes, F. (2004). Decrease of $\mathrm{H}_{2} \mathrm{O}_{2}$ plasma membrane permeability during adaptation to $\mathrm{H}_{2} \mathrm{O}_{2}$ in Saccharomyces cerevisiae. J. Biol. Chem. 279, 6501-6506. doi: 10.1074/jbc.M311818200

Brigelius-Flohé, R., and Flohé, L. (2011). Basic principles and emerging concepts in the redox control of transcription factors. Antioxid. Redox Signal. 15, 2335-2381. doi: 10.1089/ars.2010.3534

Buettner, G. R., Wagner, B. A., and Rodgers, V. G. J. (2013). Quantitative redox biology: an approach to understanding the role of reactive species in defining the cellular redox environment. Cell Biochem. Biophys. 67, 477-483. doi: 10.1007/s12013-011-9320-3

Chen, C.-Y., Willard, D., and Rudolph, J. (2009). Redox regulation of SH2domain-containing protein tyrosine phosphatases by two backdoor cysteines. Biochemistry (Mosc.) 48, 1399-1409. doi: 10.1021/bi801973z

Chen, K., Kirber, M. T., Xiao, H., Yang, Y., and Keaney, J. F. (2008). Regulation of ROS signal transduction by NADPH oxidase 4 localization. J. Cell Biol. 181, 1129-1139. doi: 10.1083/jcb.200709049

Covas, G., Marinho, H. S., Cyrne, L., and Antunes, F. (2013). Activation of Nrf2 by $\mathrm{H} 2 \mathrm{O} 2$ : de novo synthesis versus nuclear translocation. Methods Enzymol. 528, 157-171. doi: 10.1016/B978-0-12-405881-1.00009-4

Cyrne, L., Oliveira-Marques, V., Marinho, H. S., and Antunes, F. (2013). $\mathrm{H}_{2} \mathrm{O}_{2}$ in the induction of NF-кB-dependent selective gene expression. Methods Enzymol. 528, 173-188. doi: 10.1016/B978-0-12-405881-1.00010-0

Dagnell, M., Frijhoff, J., Pader, I., Augsten, M., Boivin, B., Xu, J., et al. (2013). Selective activation of oxidized PTP1B by the thioredoxin system modulates PDGF-? receptor tyrosine kinase signaling. Proc. Natl. Acad. Sci. U.S.A. 110, 13398-13403. doi: 10.1073/pnas.1302891110

Denu, J. M., and Tanner, K. G. (1998). Specific and reversible inactivation of protein tyrosine phosphatases by hydrogen peroxide: evidence for a sulfenic acid intermediate and implications for redox regulation. Biochemistry (Mosc.) 37, 5633-5642. doi: 10.1021/bi973035t

De Oliveira-Marques, V., Cyrne, L., Marinho, H., and Antunes, F. (2007). A quantitative study of NF-kappa B activation by $\mathrm{H}_{2} \mathrm{O}_{2}$ : relevance in inflammation and synergy with TNF-alpha. J. Immunol. 178, 3893-3902. doi: 10.4049/jimmunol.178.6.3893

Ferrer-Sueta, G., Manta, B., Botti, H., Radi, R., Trujillo, M., and Denicola, A. (2011). Factors affecting protein thiol reactivity and specificity in peroxide reduction. Chem. Res. Toxicol. 24, 434-450. doi: 10.1021/tx100413v

Fisher-Wellman, K. H., and Neufer, P. D. (2012). Linking mitochondrial bioenergetics to insulin resistance via redox biology. Trends Endocrinol. Metab. 23, 142-153. doi: 10.1016/j.tem.2011.12.008

Flohe, L. (1979). Glutathione peroxidase: fact and fiction. Ciba Found. Symp. 65, 95-122.
Forman, H. J. (2007). Use and abuse of exogenous $\mathrm{H}_{2} \mathrm{O}_{2}$ in studies of signal transduction. Free Radic. Biol. Med. 42, 926-932. doi: 10.1016/j.freeradbiomed.2007.01.011

Forman, H. J., Maiorino, M., and Ursini, F. (2010). Signaling functions of reactive oxygen species. Biochemistry (Mosc.) 49, 835-842. doi: 10.1021/bi9020378

Forstrom, J. W., and Tappel, A. L. (1979). Donor substrate specificity and thiol reduction of glutathione disulfide peroxidase. J. Biol. Chem. 254, 2888-2891.

Haque, A., Andersen, J. N., Salmeen, A., Barford, D., and Tonks, N. K. (2011). Conformation-sensing antibodies stabilize the oxidized form of PTP1B and inhibit its phosphatase activity. Cell 147, 185-198. doi: 10.1016/j.cell.2011.08.036

Huang, B. K., and Sikes, H. D. (2014). Quantifying intracellular hydrogen peroxide perturbations in terms of concentration. Redox Biol. 2, 955-962. doi: 10.1016/j.redox.2014.08.001

Irani, K., Xia, Y., Zweier, J. L., Sollott, S. J., Der, C. J., Fearon, E. R., et al. (1997). Mitogenic signaling mediated by oxidatnts in ras-transformed fibroblasts. Science 275, 1649-1652. doi: 10.1126/science.275.5306.1649

Iwakami, S., Misu, H., Takeda, T., Sugimori, M., Matsugo, S., Kaneko, S., et al. (2011). Concentration-dependent dual effects of hydrogen peroxide on insulin signal transduction in H4IIEC hepatocytes. PLOS ONE 6:e27401. doi: 10.1371/journal.pone.0027401

LaButti, J., Chowdhury, G., Reilly, T. J., and Gates, K. S. (2007). Redox regulation of protein tyrosine phosphatase $1 \mathrm{~B}$ (PTP1B) by peroxymonophosphate (= O3POOH). J. Am. Chem. Soc. 129:5320. doi: 10.1021/ja070194j

Lee, S. R., Kwon, K. S., Kim, S. R., and Rhee, S. G. (1998). Reversible inactivation of protein-tyrosine phosphatase 1B in A431 cells stimulated with epidermal growth factor. J. Biol. Chem. 273, 15366-15372. doi: 10.1074/jbc.273.25.15366

Le Moan, N., Clement, G., Le Maout, S., Tacnet, F., and Toledano, M. B. (2006). The Saccharomyces cerevisiae proteome of oxidized protein thiols: contrasted functions for the thioredoxin and glutathione pathways. J. Biol. Chem. 281, 10420-10430. doi: 10.1074/jbc.M513346200

Mahadev, K., Zilbering, A., Zhu, L., and Goldstein, B. J. (2001). Insulin-stimulated hydrogen peroxide reversibly inhibits protein-tyrosine phosphatase $1 \mathrm{~b}$ in vivo and enhances the early insulin action cascade. J. Biol. Chem. 276, 21938-21942. doi: 10.1074/jbc.C100109200

Makino, N., Sasaki, K., Hashida, K., and Sakakura, Y. (2004). A metabolic model describing the $\mathrm{H} 2 \mathrm{O} 2$ elimination by mammalian cells including $\mathrm{H} 2 \mathrm{O} 2$ permeation through cytoplasmic and peroxisomal membranes: comparison with experimental data. Biochim. Biophys. Acta 1673, 149-159. doi: 10.1016/j.bbagen.2004.04.011

Marinho, H. S., Cyrne, L., Cadenas, E., and Antunes, F. (2013a). H2O2 delivery to cells: steady-state versus bolus addition. Methods Enzymol. 526, 159-173. doi: 10.1016/B978-0-12-405883-5.00010-7

Marinho, H. S., Cyrne, L., Cadenas, E., and Antunes, F. (2013b). The cellular steadystate of $\mathrm{H}_{2} \mathrm{O}_{2}$ : latency concepts and gradients. Methods Enzymol. 527, 3-19. doi: 10.1016/B978-0-12-405882-8.00001-5

Marinho, H. S., Real, C., Cyrne, L., Soares, H., and Antunes, F. (2014). Hydrogen peroxide sensing, signaling and regulation of transcription factors. Redox Biol. 2, 535-562. doi: 10.1016/j.redox.2014.02.006

Martínez-Acedo, P., Núñez, E., Gómez, F. J. S., Moreno, M., Ramos, E., Izquierdo-Álvarez, A., et al. (2012). A novel strategy for global analysis of the dynamic thiol redox proteome. Mol. Cell. Proteomics 11, 800-813. doi: 10.1074/mcp.M111.016469

Meng, T.-C., Fukada, T., and Tonks, N. K. (2002). Reversible oxidation and inactivation of protein tyrosine phosphatases in vivo. Mol. Cell 9, 387-399. doi: 10.1016/S1097-2765(02)00445-8

Miller, E. W., Dickinson, B. C., and Chang, C. J. (2010). Aquaporin-3 mediates hydrogen peroxide uptake to regulate downstream intracellular signaling. Proc. Natl. Acad. Sci. U.S.A. 107, 15681-15686. doi: 10.1073/pnas.10057 76107

Mishina, N. M., Tyurin-Kuzmin, P. A., Markvicheva, K. N., Vorotnikov, A. V., Tkachuk, V. A., Laketa, V., et al. (2011). Does cellular hydrogen peroxide diffuse or act locally? Antioxid. Redox Signal. 14, 1-7. doi: 10.1089/ars. 2010.3539

Oakley, F. D., Abbott, D., Li, Q., and Engelhardt, J. F. (2009). Signaling components of redox active endosomes: the redoxosomes. Antioxid. Redox Signal. 11, 1313-1333. doi: 10.1089/ARS.2008.2363

Oliveira-Marques, V., Silva, T., Cunha, F., Covas, G., Marinho, H. S., Antunes, F., et al. (2013). A quantitative study of the cell-type specific modulation 
of c-Rel by hydrogen peroxide and TNF-? Redox Biol. 1, 347-352. doi: 10.1016/j.redox.2013.05.004

Parsons, Z. D., and Gates, K. S. (2013). Thiol-dependent recovery of catalytic activity from oxidized protein tyrosine phosphatases. Biochemistry (Mosc.) 52, 6412-6423. doi: 10.1021/bi400451m

Paulsen, C. E., Truong, T. H., Garcia, F. J., Homann, A., Gupta, V., Leonard, S. E., et al. (2012). Peroxide-dependent sulfenylation of the EGFR catalytic site enhances kinase activity. Nat. Chem. Biol. 8, 57-64. doi: 10.1038/nchembio.736

Rasband, W. (1997). ImageJ, U. S. National Institutes of Health. Bethesda, MD. Available online at: http://rsb.info.nih.gov/ij/, 1997-2006

Rawat, S. J., Creasy, C. L., Peterson, J. R., and Chernoff, J. (2013). The tumor suppressor Mst1 promotes changes in the cellular redox state by phosphorylation and inactivation of peroxiredoxin-1 protein. J. Biol. Chem. 288, 8762-8771. doi: 10.1074/jbc.M112.414524

Rinna, A., Torres, M., and Forman, H. J. (2006). Stimulation of the alveolar macrophage respiratory burst by ADP causes selective glutathionylation of protein tyrosine phosphatase 1B. Free Radic. Biol. Med. 41, 86-91. doi: 10.1016/j.freeradbiomed.2006.03.010

Sies, H. (2014). Role of metabolic $\mathrm{H} 2 \mathrm{O} 2$ generation: redox signalling and oxidative stress. J. Biol. Chem. 289, 8735-8741. doi: 10.1074/jbc.R113.544635

Tanner, J. J., Parsons, Z. D., Cummings, A. H., Zhou, H., and Gates, K. S. (2011). Redox regulation of protein tyrosine phosphatases: structural and chemical aspects. Antioxid. Redox Signal. 15, 77-97. doi: 10.1089/ars. 2010.3611

Trindade, D. F., Cerchiaro, G., and Augusto, O. (2006). A role for peroxymonocarbonate in the stimulation of biothiol peroxidation by the bicarbonate/carbon dioxide pair. Chem. Res. Toxicol. 19, 1475-1482. doi: 10.1021/tx060146x

Tschopp, J., and Schroder, K. (2010). NLRP3 inflammasome activation: the convergence of multiple signalling pathways on ROS production? Nat. Rev. Immunol. 10, 210-215. doi: 10.1038/nri2725

Van Eunen, K., Bouwman, J., Daran-Lapujade, P., Postmus, J., Canelas, A. B., Mensonides, F. I. C., et al. (2010). Measuring enzyme activities under standardized in vivo-like conditions for systems biology. FEBS J. 277, 749-760. doi: $10.1111 /$ j.1742-4658.2009.07524.x
Van Eunen, K., Kiewiet, J. A. L., Westerhoff, H. V., and Bakker, B. M. (2012). Testing biochemistry revisited: how in vivo metabolism can be understood from in vitro enzyme kinetics. PLoS Comput Biol 8:e1002483. doi: 10.1371/journal.pcbi. 1002483

Voit, E. (1991). Canonical Nonlinear Modeling: S-System Approach to Understanding Complexity. New York, NY: Van Nostrand Reinhold.

Winterbourn, C. C., and Hampton, M. B. (2008). Thiol chemistry and specificity in redox signaling. Free Radic. Biol. Med. 45, 549-561. doi: 10.1016/j.freeradbiomed.2008.05.004

Woo, H. A., Yim, S. H., Shin, D. H., Kang, D., Yu, D.-Y., and Rhee, S. G. (2010). Inactivation of peroxiredoxin i by phosphorylation allows localized $\mathrm{H} 2 \mathrm{O} 2 \mathrm{accu}-$ mulation for cell signaling. Cell 140, 517-528. doi: 10.1016/j.cell.2010.01.009

Zhou, H., Singh, H., Parsons, Z. D., Lewis, S. M., Bhattacharya, S., Seiner, D. R., et al. (2011). The Biological Buffer Bicarbonate/CO 2 Potentiates $\mathrm{H}_{2} \mathrm{O}_{2}$ -Mediated Inactivation of Protein Tyrosine Phosphatases. J. Am. Chem. Soc. 133, 15803-15805. doi: 10.1021/ja2077137

Conflict of Interest Statement: The authors declare that the research was conducted in the absence of any commercial or financial relationships that could be construed as a potential conflict of interest.

Received: 18 July 2014; accepted: 15 September 2014; published online: 02 October 2014.

Citation: Brito PM and Antunes F (2014) Estimation of kinetic parameters related to biochemical interactions between hydrogen peroxide and signal transduction proteins. Front. Chem. 2:82. doi: 10.3389/fchem.2014.00082

This article was submitted to Cellular Biochemistry, a section of the journal Frontiers in Chemistry.

Copyright $(2014$ Brito and Antunes. This is an open-access article distributed under the terms of the Creative Commons Attribution License (CC BY). The use, distribution or reproduction in other forums is permitted, provided the original author(s) or licensor are credited and that the original publication in this journal is cited, in accordance with accepted academic practice. No use, distribution or reproduction is permitted which does not comply with these terms. 